\title{
بناء مقياس للقيم الاجتماعية للاعبي الاهوكي
}

*م.م/محمود أحمد مصطفي عبد المقصود

يعد التغير احد ابرز السمات تواجه عالمنا اليوم وبخاصة مجتمعنا المصري ومن أهم مظاهر هذا التغير انفتاح العالم دون قيود وتتوعه بصورة لانهائية وهذا التغير ذو طابع مستمر في حياتتا ومن ثم فعلينا مواكبته في كافة مجالات الحياة وان المجتمعات باختلاف ألو انها و أحجامها تمر بتغير ات مختلفة خصوصا من حيث العناصر التقافية التي تتتاولها ومن حيث معدل سرعتها ولعل مرد ذلك يعود إلي تو افر أو غزارة وسائل الاتصال المختلفة بين أرجاء العالم إلي جانب التقدم العلمي الذي أعان علي استغلال البيئات الطبيعية وتسخير ها لخير البشرية فليس هناك ثبات مطلق في العلاقات الاجتماعية وبالتالي في المجتمعات فالفكرة السائدة أن كل شيء يتغير في المجتمع هو تغير اجتماعي فالتغير ظاهرة طبيعية تخضع لها كل قو اميس الحياة الأمر الذي دفع البعض إلي القول بأنه ليست هناك مجتمعات و إنما هناك عمليات اجتماعية وتفاعلات في تغير مستمر و إن التغير الاجتماعي من أهم الظواهر المصاحبة لهذه المجتمعات البشرية بل هو في حقيقة الأمر أهم خصائصها فالمجتمعات دائمة التطور و التغير لان ذلك وحده هو الذي يكتب لها البقاء و الاستمر ار و النمو و المجتمعات التي هوه

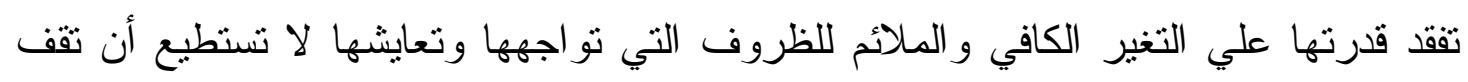
طويلا أو تتنافس باقتدار وتكافؤ مع حركة المجتمعات الأخرى .

تلعب القيم دور ا مهما في تكوين شخصية الفرد فمن خلال تعلمها و الالتز ام بها يمكن ان تشكل فردا قويا متحلياً بالخلق و السلوك القويم فالقيم تقوم بتزويد الفرد بشعور من التوجيه الداخلي وتتير الجماعة بالاتجاه العام وتزودها بكيفية بناء أسس العمل الفردي و الجماعي وتستعمل كوسيلة من اجل الحكم علي سلوك الأفر اد وتمكن الفرد من ضبط نفسه وتمكنه من

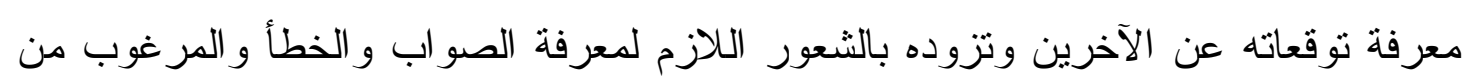

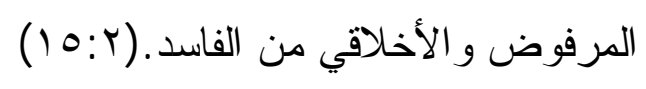

*مدرس مساعد بقسم العلوم التربوية والتفسية والاجتماعية -كلية التربية الرياضية بنين جامعة الزقازيق 
تقوم القيم بتوفير البيئة التربوية المناسبة التي تحقق المزيد من فهم الأفراد واستيعابهم

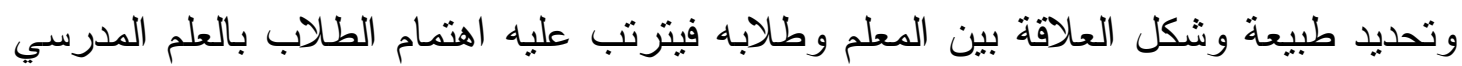

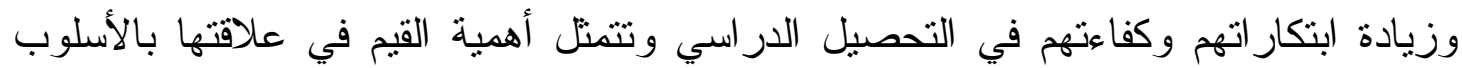

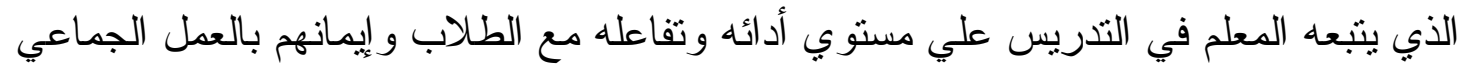
وتقدير قيمة الوقت ونوع التخصص الذي يرغبه الطالب لكي يحقق فيه النوازن الذي يستهدفه المجتمع في تكوين شبابه في النواحي القيمية و الوجدانية و الثقافية ولذا ينبغي أن تتركز التربية في تكوين اتجاه سلبي نحو القيم المر اد تعديلها و اتجاه ايجابي نحو القيم المستهدفة حتى تتدرج علي السلم القيمي للمجتمع وهذا يؤكد أهمية الدور الذي يمكن أن تقوم به المدرسة في مجال غرس وتتمية القيم لاي المتعلمين من خلال مناهجها. ( (

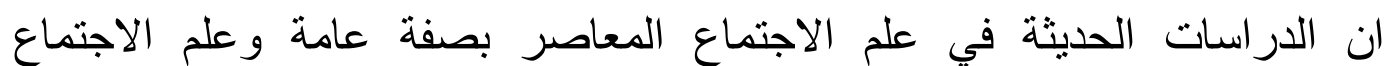

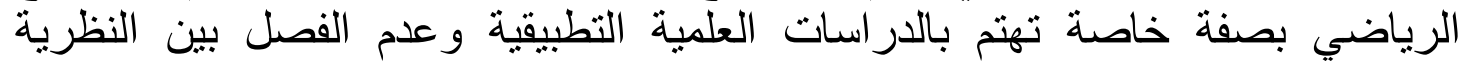

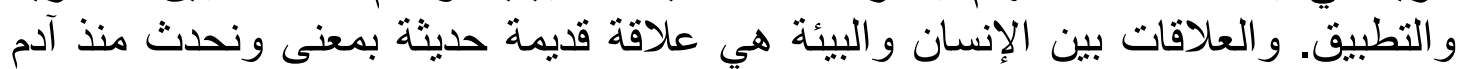

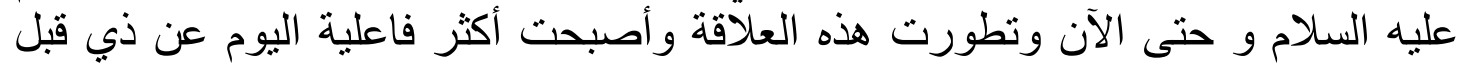

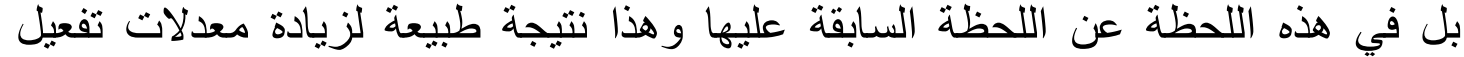

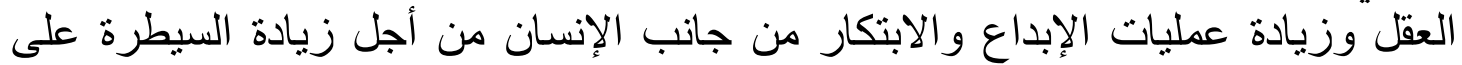

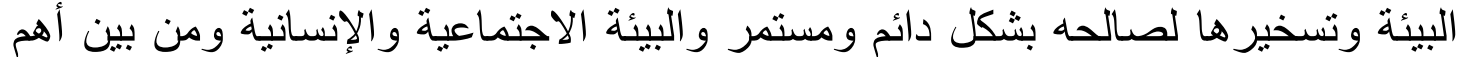

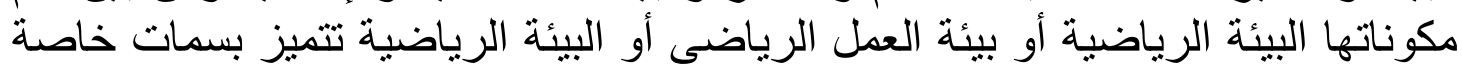

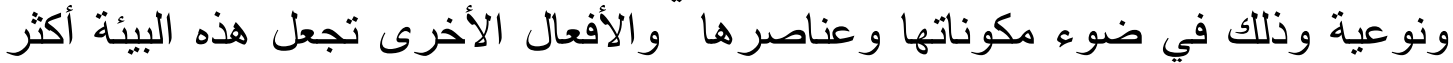

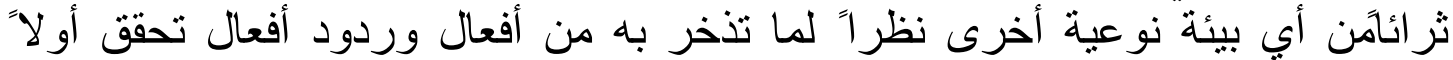

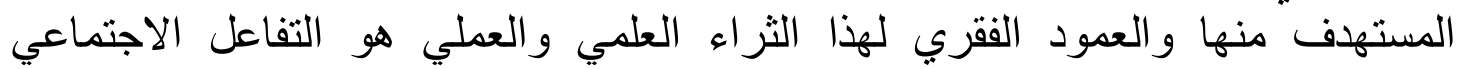

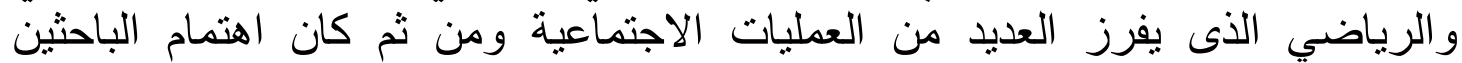

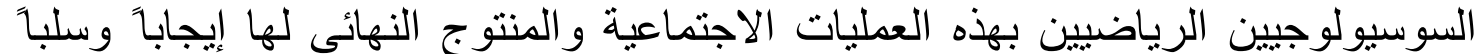

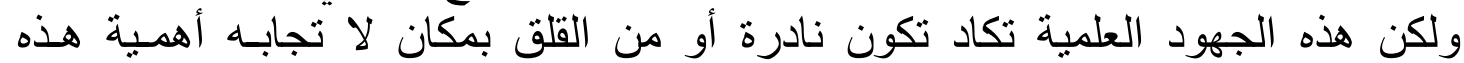

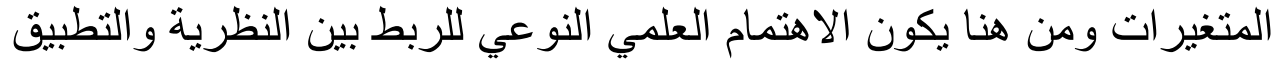

\section{$(11 \cdot: 4)$}

وتعد القيم الاجتماعية والأخلاق من اقوي ما تبني به المجتمعات ومن أهم الروابط التي

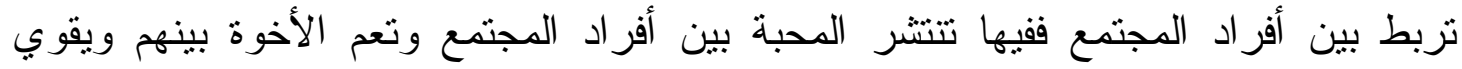

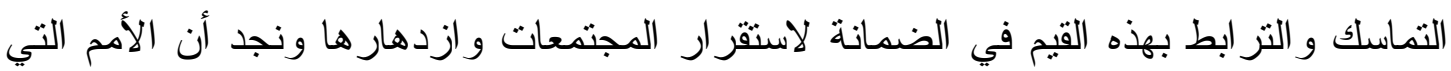

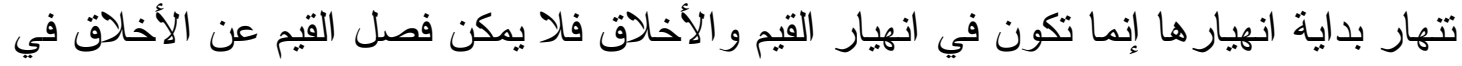

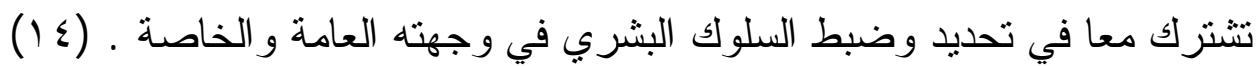
وتعد القيم الاجتماعية احد المعايير المهمة التي تسهم بدرجة كبيرة في تقويم وبناء

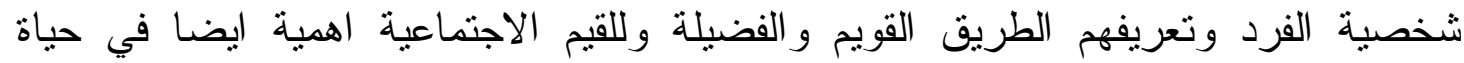


المجتمع والافر اد فهي تمس العلاقات الانسانية بصورها كافة وهي معايير واهداف تسعي

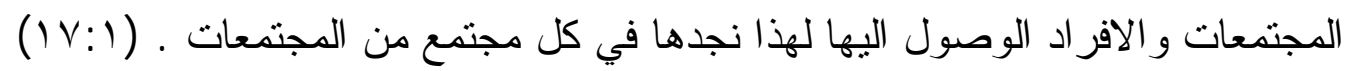
كما تعد القيم الاجتماعية و الأخلاق من اقوي ما تبني به المجتمعات ومن أهم الروابط

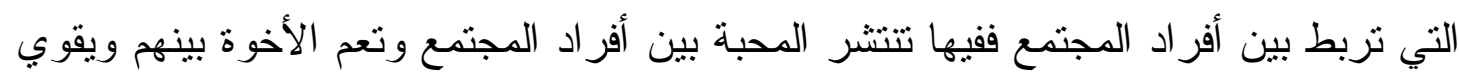

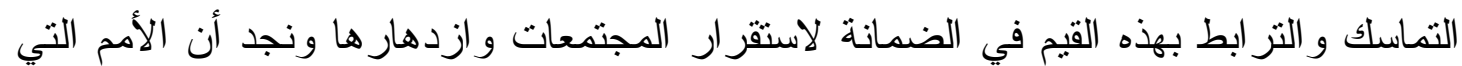

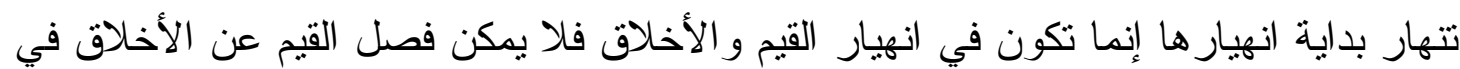

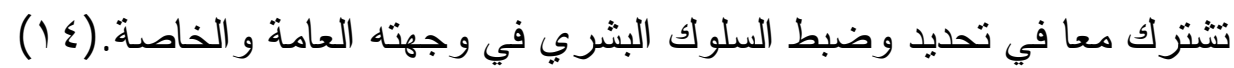

\section{مشكاكة البحث}

بالرغم من الأهمية المتزايدة للقيم الاجتماعية في الرياضة وما بمكن أن نؤديه من دور و اضح وفعال في الارتقاء بسلوكيات ودو افع الأفر اد بصفه عامه وبالعمليات الاجتماعية بصفة الاهنة

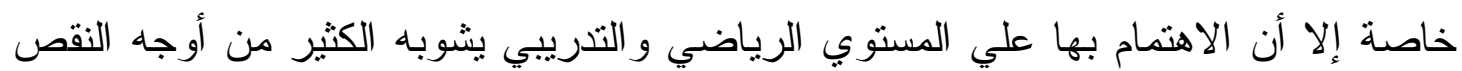

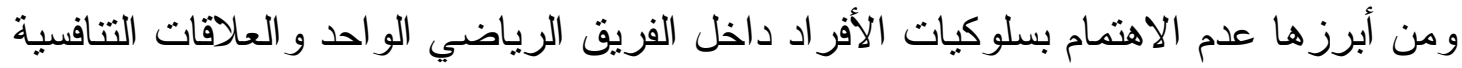
بين الفرق المختلفة الأمر الذي يؤدي إلي إصابة الفريق الرياضي بحالة من الخلل القيمي وان

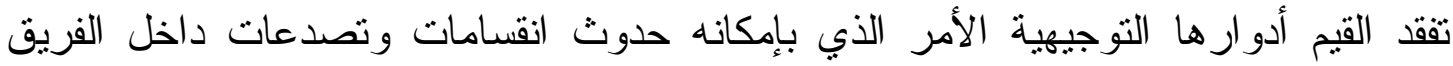

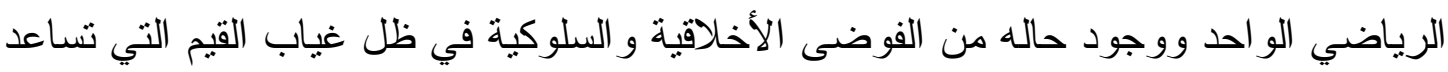

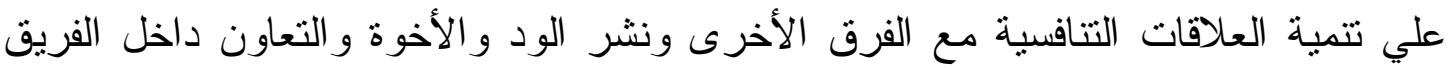
الواحد الامر الذي يستدعي دراسة القيم الاجتماعية للاعبين الامر الذي يعمل علي تدعيم الاحت

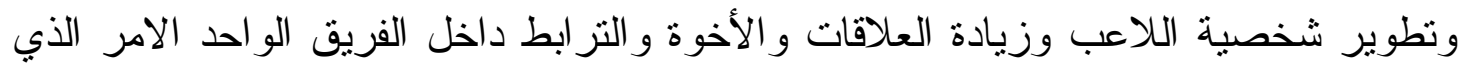
يعود بالنفع علي نتائج و اهداف الفريق.

ويري الباحث ان القيم الاجتماعية تتمتل أهيتها في رياضة هوكي الميدان باعتبار ها لعبة

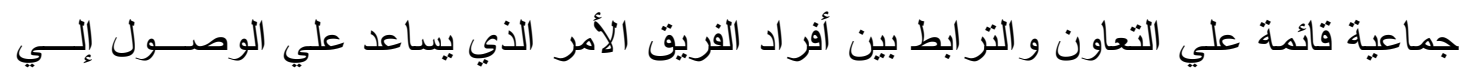

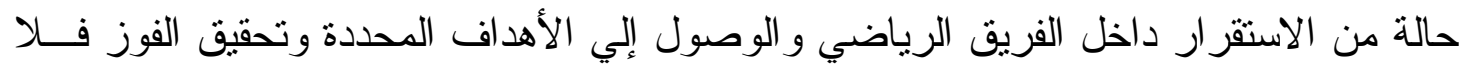

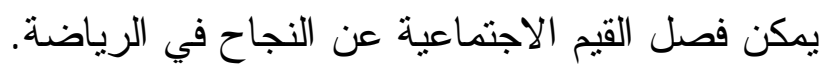

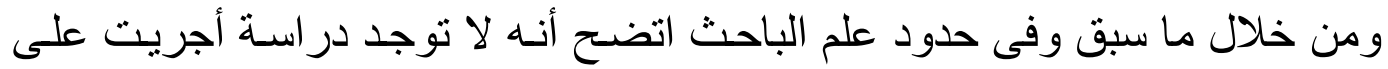

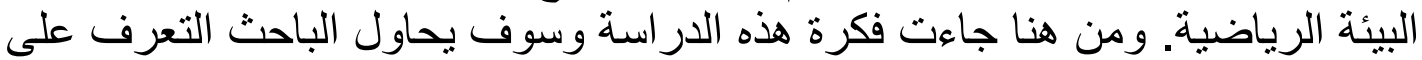

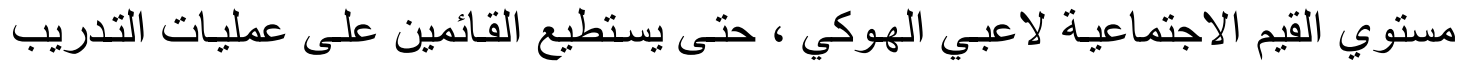

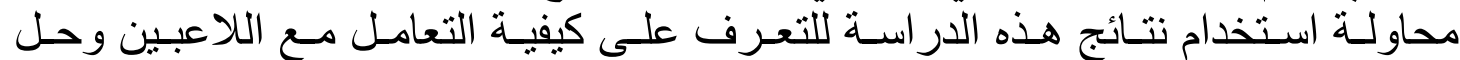

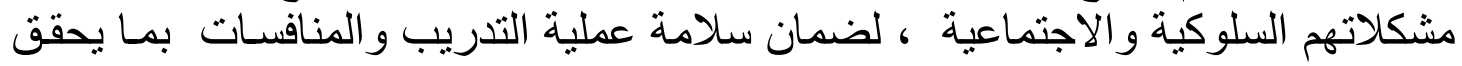
الوصول إلى المستويات العليا دولياً. 


\section{اهمية الدراسة:}

الاهمية النظرية

تساعد هذه الدر اسة في القدرة علي التعرف علي القيم الاجتماعية للاعبي الهوكي .

الاهمية التطبيقية لهدية

تذليل العديد من الصعوبات المرتبطة بالثق السلوكي والاجتماعي لرياضيين المستويات

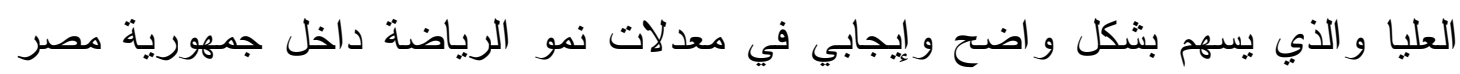

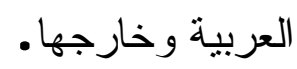

\section{أهداف الدراسة:}

يهدف هذا البحث إلي التعرف علي مستوي القيم الاجتماعية للاعبي الهوكي وذلك من خلال:

$$
\begin{aligned}
& \text { • بناء مقياس للقيم الاجتماعية للاعبي الهوكي. } \\
& \text { • التعرف علي مستوي القيم الاجتماعية للاعبي الهوكي. } \\
& \text { تساؤلات البحته: } \\
& \text { • ما هي أبعاد مقياس القيم الاجتماعية؟ } \\
& \text { • ما مستوي القيم الاجتماعية للاعبي الهوكي؟ }
\end{aligned}
$$

تعرف بأنها مجمو عة من المعايير للسلوك الاجتماعي و الإنساني ولها تقدير و اتزان معين

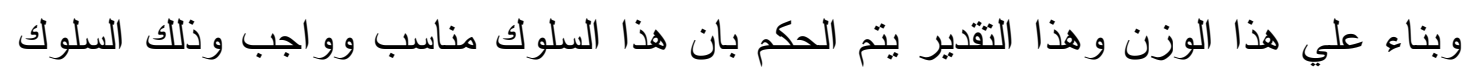

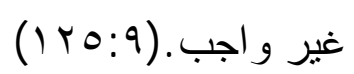




\section{اولا: الدراسات السابقة العربية:}

\section{جلول (1)}

\begin{tabular}{|c|c|c|c|c|c|c|}
\hline \multirow{2}{*}{ 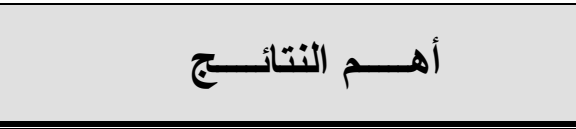 } & \multicolumn{2}{|c|}{ الإجـــــــــاءعات } & \multirow{2}{*}{ هدف الدر اسة } & \multirow{2}{*}{ عنوان الار اسة } & \multirow{2}{*}{ اسم الباحث والسنة } & \multirow{2}{*}{ r } \\
\hline & العينة & المنهج & & & & \\
\hline 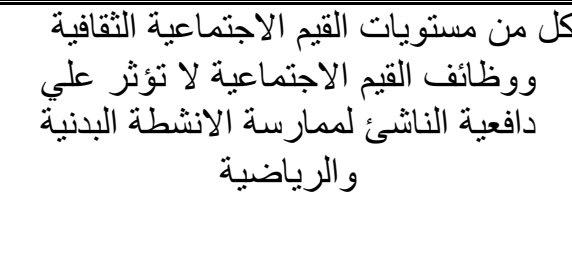 & 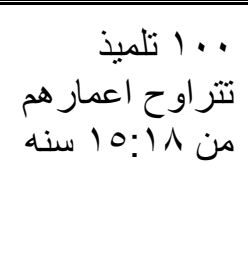 & المنتخجم الباحفي & 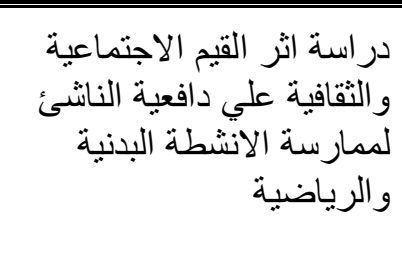 & الاجتماعية والثيثافية الثية & مزيان سليم ، بن زين & $\overline{11}$ \\
\hline 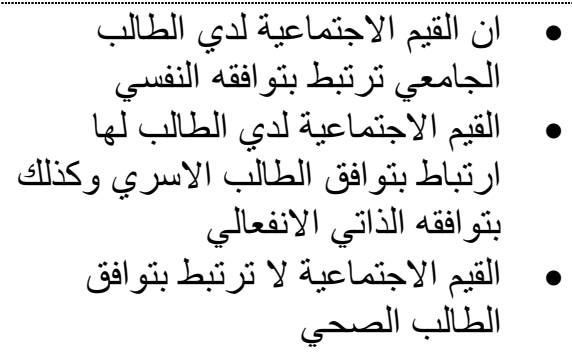 & o.r طالب & المنهج الوصفي & 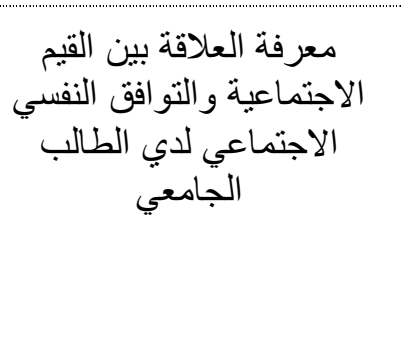 & 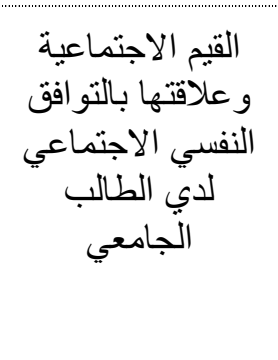 & 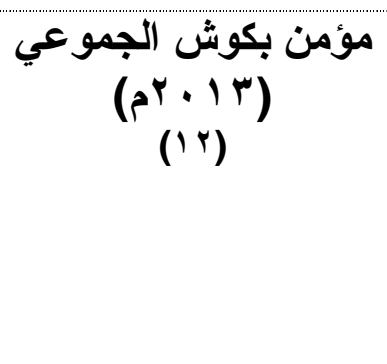 & r \\
\hline
\end{tabular}




\section{تابع جلول (ا)}

\begin{tabular}{|c|c|c|c|c|c|c|}
\hline \multirow{2}{*}{ 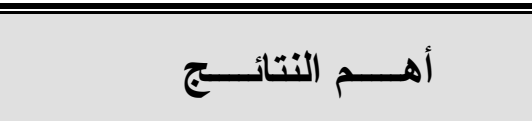 } & \multicolumn{2}{|c|}{ الإجــــر اءات } & \multirow{2}{*}{ هدف الاراسة } & \multirow{2}{*}{ عنوان الارساسة } & \multirow{2}{*}{ اسم الباحث و السنة } & \multirow[b]{2}{*}{ p } \\
\hline & العينة & المنهج & & & & \\
\hline 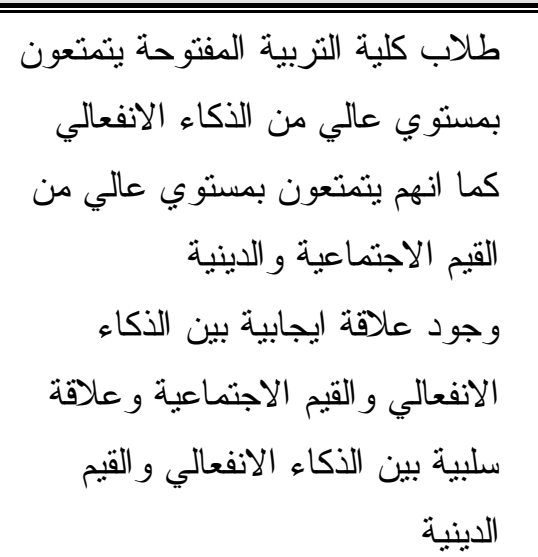 & 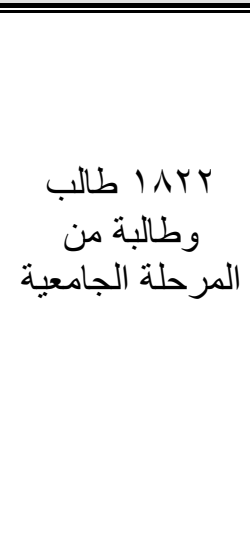 & المنهج الوصفي & 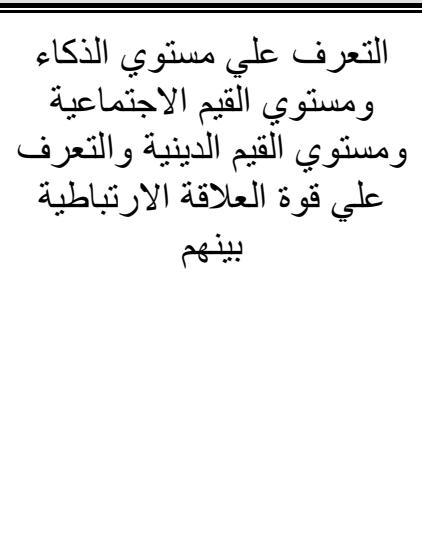 & 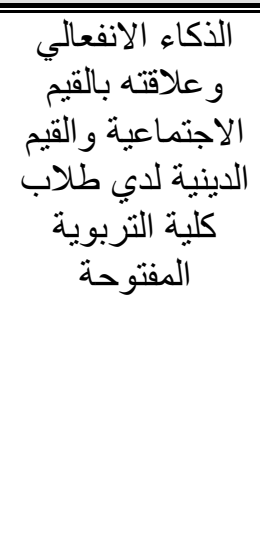 & 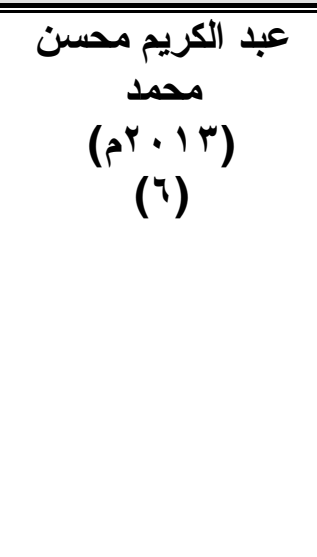 & $\overline{\bar{r}}$ \\
\hline 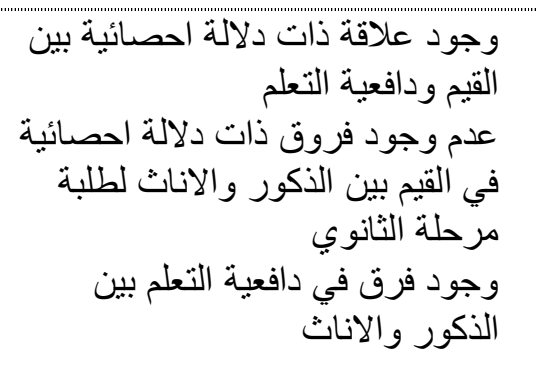 & الثانوي ألميذ من & الدنهج الوصفي & التهل العلاقة بلين القيم ودافعية & 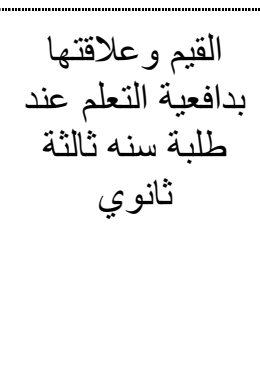 & 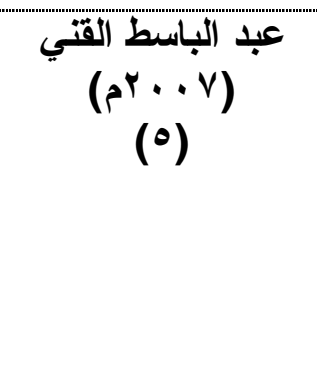 & $\varepsilon$ \\
\hline
\end{tabular}




\section{تابع جدول (ا)}

\begin{tabular}{|c|c|c|c|c|c|c|}
\hline \multirow{2}{*}{ أهـــــم النتائســـج } & \multicolumn{2}{|c|}{ الإجـــــــاءات } & \multirow{2}{*}{ هدف الدراسة } & \multirow{2}{*}{ عنوان الدراسة } & \multirow{2}{*}{ اسم الباحث والسنة } & \multirow[b]{2}{*}{ r } \\
\hline & العينة & المنهج & & & & \\
\hline 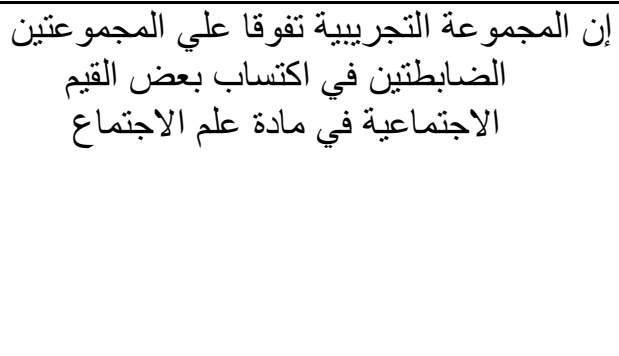 & 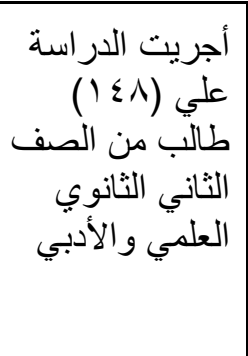 & والمنهج التجريبي الوصفي & 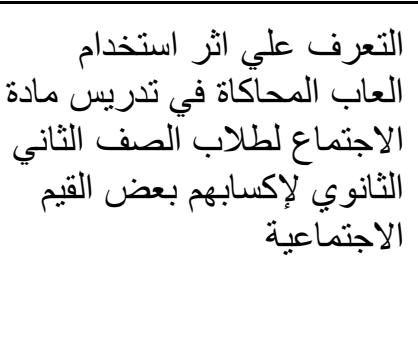 & 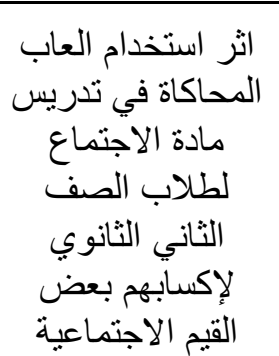 & 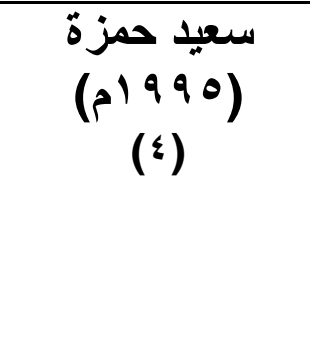 & 0 \\
\hline
\end{tabular}


ثانيا: الدر اسات السابقة الأجنبية:

جدول (r)

\begin{tabular}{|c|c|c|c|c|c|c|}
\hline \multirow{2}{*}{ 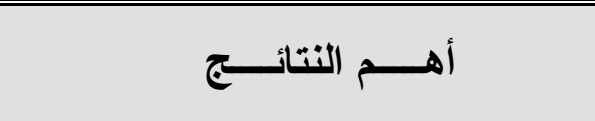 } & \multicolumn{2}{|c|}{ الإجــــــاءات } & \multirow{2}{*}{ هدف الدراسة } & \multirow{2}{*}{ عنوان الارسة } & \multirow{2}{*}{ اسم الباحث و السنة } & \multirow{2}{*}{ p } \\
\hline & العينة & المنهج & & & & \\
\hline 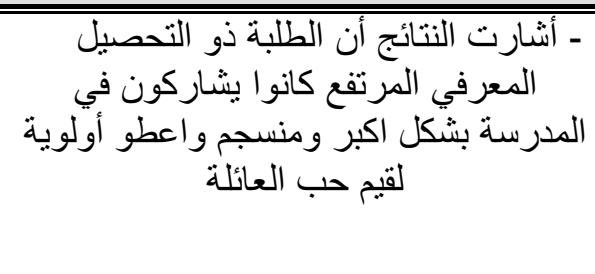 & 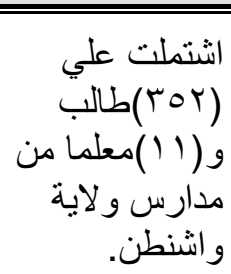 & المنهج الوصفي & 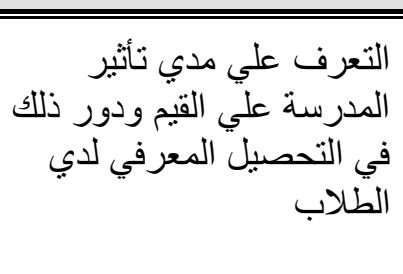 & 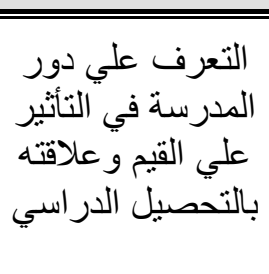 & $\begin{array}{c}\text { "craig" كريج } \\
(p) q \wedge q) \\
(1 \leqslant)\end{array}$ & $\overline{1}$ \\
\hline 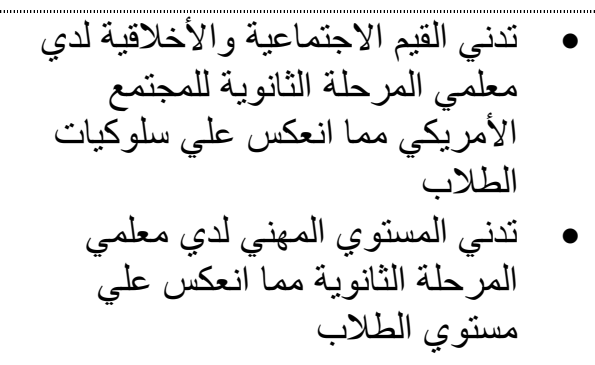 & 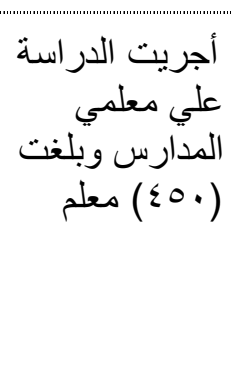 & المنهج الوصفي & 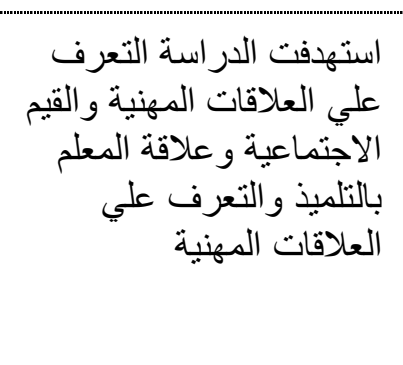 & 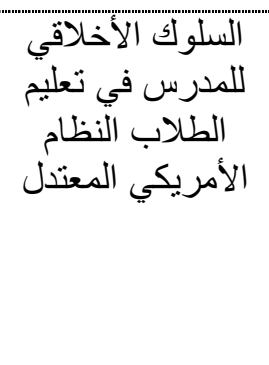 & 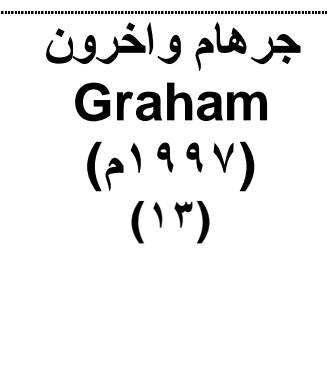 & r \\
\hline
\end{tabular}




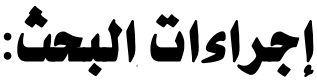

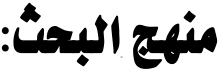

استخدم الباحث أسلوب المنهج الوصفي لمناسبته مع طبيعة إجر اءات البحث.

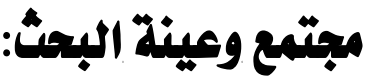

يتكون مجتمع البحث من لاعبي رياضة هوكي الميدان بمحافظة الثرقية و المسلون بسجلات الاتحاد المصري للهوكي ونم اختبار عينة البحث بالطريقة العمدية واثتملت علي لاعبي الهوكي بنادي

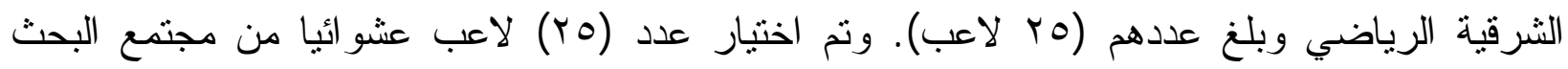
لإجر اء الدر اسة الاسنطلاعية وبذلك تصبح عينة تجربة البحث الاساسية (ro) لاعب و عينة تجربة البحث

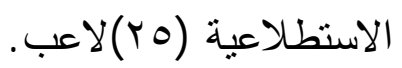

و الجدول التالي يوضح تصنيف عينة البحث:

جدول (r)

تصنيف عينة البحث

\begin{tabular}{|c|c|c|c|c|c|c|c|}
\hline \multicolumn{2}{|c|}{ المجموع } & \multicolumn{2}{|c|}{ العينة الأساسية } & \multicolumn{2}{|c|}{ العينة الاستطلاعية } & \multirow{2}{*}{ /النادي /اسة } & \\
\hline النسبة المئوية & العدد العد & النسبة المئوية & العدد العد & النسبة المئوية & 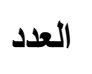 & & r \\
\hline$\% 4$ & r. & $\%$ & ro & $\%$ \%. & 0 & نادي الثرقية & 1 \\
\hline$\%$ \%. & 1. & - & - & $\% \leftleftarrows$ & 1. & النادي الثشبان & r \\
\hline$\% r$. & 1. & - & - & $\% \leftleftarrows-$ & 1. & مركز شباب & $r$ \\
\hline$\% 1 \ldots$ & 0. & $\% ०$. & ro & $\% ०$. & ro & المجموع & $\xi$ \\
\hline
\end{tabular}

يوضح جدول (r) النسبة المئوية لتصنيف عينة البحث الأساسية والاسنطلاعية.

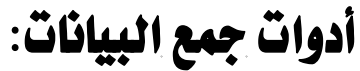

قام الباحث بعض استمارة تحتوي علي القيم الاجتماعية علي السادة الخبر اءو عددهم (1) لاختبار أنسب القيم الاجتماعية المناسبة لطبيعة هذه الدر ساسة. 


\section{المسح المرجعي و المقابلة الشخصية:}

في ضوء اهداف الدراسة قام الباحث ببناء مقياس القيم الاجتماعية وذللك من خلال مراجعة

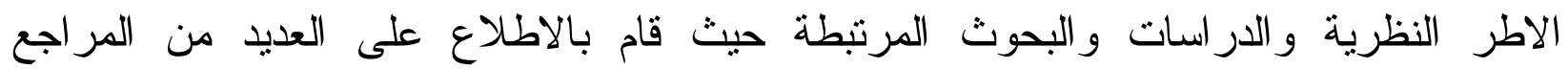
و الدوريات و المجلات العلمية في مجال علم الاجتماع و القياس والتقويم وتحليل المراجع العلمية المرتبطة بالقيم الاجتماعية وتوصل الباحث الى أن المقياس يمر بمجموعة من المر احل حتى يتم

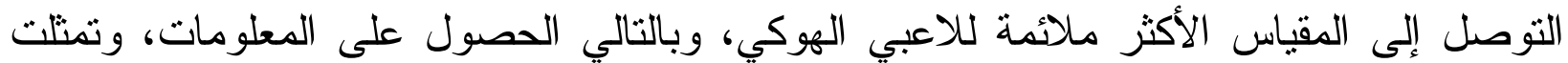
هذه المر احل في:

تحديد الهـف من المقياس:

بناء مقياس للقيم الاجتماعية للتعرف علي مستوي القيم الاجتماعية للاعبين.

تحديد محاور المقياس:

تم تحديد المحاور الاساسية للمقياس من خلال المسح الثامل للمر اجع العلمية و الاطر النظرية و الدر اسات و البحوث المرتبطة، كما قام الباحث بمقابلة من افر اد مجتمع الدر اسة من لاعبي الهوكي

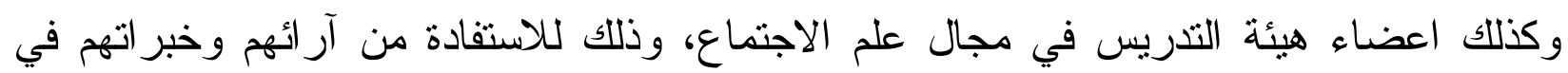
وضع تصور مبئي لبعض جو انب الدر سة حيث تمكن الباحث من تحديد ستة محاور وهي:

1 - ميمة الانتماء للفريق.

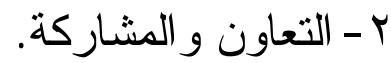

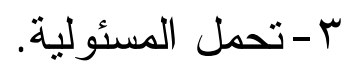

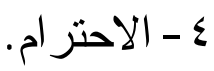

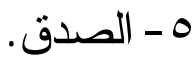

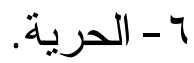

جدول (ع)

الأهمية النسبية لمحاور مقياس القيم الاجتماعية طبقاً لآراء الخبراء ن= 11

\begin{tabular}{|c|c|c|}
\hline النسبة المئوية & التكرار & المحور \\
\hline$\% 1 \ldots$ & 11 & قيمة الانتماء للفريق \\
\hline$\% 9 . .91$ & 1. & التعاون و المشاركة \\
\hline$\% 1 \ldots$ & 11 & تحمل المسئولية \\
\hline$\%$ \%1.Ar & 9 & الاحتر ام \\
\hline$\% 9 . .91$ & 1. & الصدق \\
\hline$\%$ \%1.Ar & 9 & الحرية \\
\hline
\end{tabular}


يوضح جدول (ع) أن محور قيمة الانتماء للفريق ومحور تحمل المسئولية احتـلـل المركــز الأول

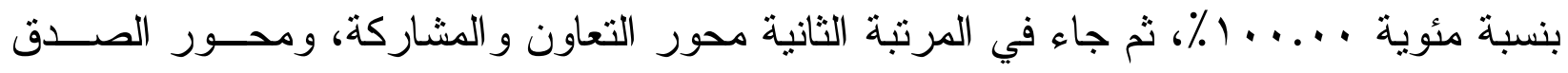

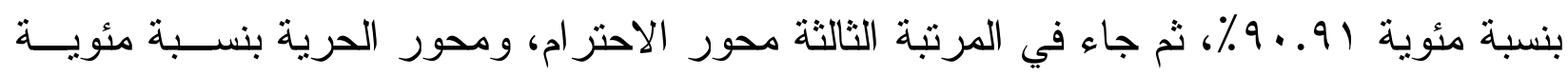
\% A . A

صياغة وتحديد عبار ات كل بعد من محاور المقياس: في ضوء الفهم و التحليل النظري الخاص بكل محور تم إعداد وصياغة العبار ات تحت كل محور من المحاور الستة كلاً حسب طبيعته وقد راع الباحث عند صياغة العبار ات أن تكون و اضحة

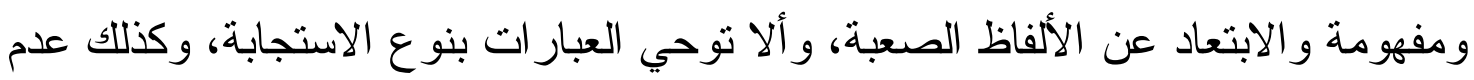

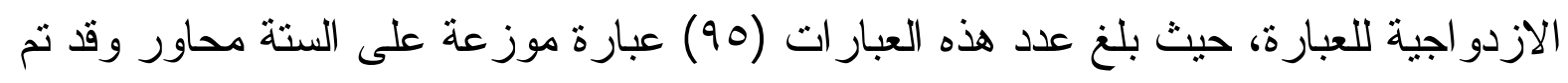

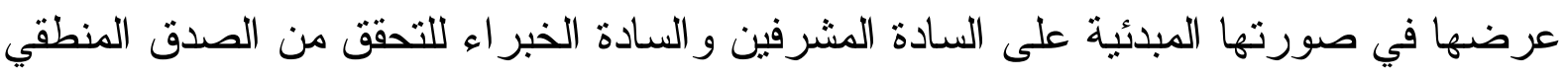
و التحقق من مدى انتماء العبار ات للمحور الخاص بها وتحديد ميز ان التقدير الخاص بالمقياس موزعه كالاتي كما يوضح جدول (0):

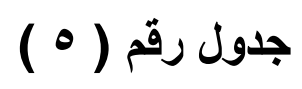

محاور مقياس القيم الاجتماعية وعدد عبار ات كل محور

\begin{tabular}{|c|c|c|}
\hline عدد العبارات & المحور & المقياس \\
\hline 11 & - قيمة الاتثماء للقريق. & \\
\hline 19 & - التعاون و المشاركة. & \\
\hline 19 & - تحمل المسئولية. & ac \\
\hline 10 & - الاحترام. & اهيخ البجمسية \\
\hline 10 & - الصدق. & \\
\hline ir & - - الحرية - & \\
\hline 9 9 عبارة & المجموع & \\
\hline
\end{tabular}

عرض الصورة المبائية على الخبر اء:

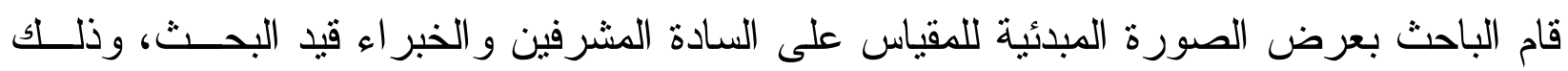

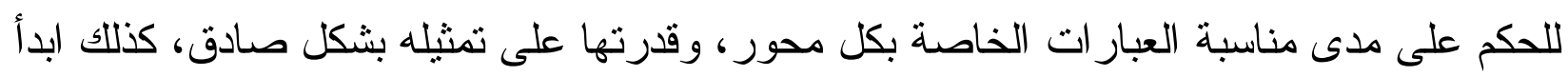
الر أي بالحذف أو الإضافة أو التعديل في صياغة أي عبارة، وجدول (ج) يوضح ذللك: 
جدول (7) جان (7)

النسبة المئوية لآراء الخبراء في عبارات مقياس القيم الاجتماعية ن= 11

\begin{tabular}{|c|c|c|c|c|c|c|c|c|c|c|c|}
\hline المحور & p & الخحور & r & المحور البع & r & المحور & p & المحور & r & المحور & b \\
\hline$\% 9 \cdot .91$ & 1 & $\% .9 . .91$ & 1 & $\% .9 . .91$ & 1 & $\% 1 \ldots$ & 1 & $\% 1 \ldots$ & 1 & $\% 9 . .91$ & 1 \\
\hline \% \% & $r$ & $\%$ \% I. r & $r$ & $\% 1 \ldots$ & $r$ & $\% \wedge I . \wedge r$ & $r$ & \%.7เ & $r$ & $\% \leq 0 . \leqslant 0$ & $r$ \\
\hline$\% \wedge 1 . \wedge r$ & r & $\% .9 . .91$ & r & $\% .9 . .91$ & r & 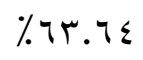 & r & $\% 1 \ldots$ & r & $\% \wedge 1 . \wedge r$ & r \\
\hline$\% 1 \ldots$ & $\varepsilon$ & $\% \wedge 1 . \wedge r$ & $\varepsilon$ & $\% 0 \leqslant .00$ & $\varepsilon$ & $\% 9 . .91$ & $\varepsilon$ & \%า & $\varepsilon$ & $\% 1 \ldots$ & $\varepsilon$ \\
\hline$\% 0 \leqslant .00$ & 0 & $\% 1 \ldots$ & 0 & $\% 1 \ldots$ & 0 & $\% 9 . .91$ & 0 & $\% \wedge I . \wedge r$ & 0 & $\%$ \% 1.00 & 0 \\
\hline \% & 7 & $\% 1 \ldots$ & 7 & $\% 0 \leqslant .00$ & 7 & \%าr.7 & 7 & $\% 1 \ldots$ & 7 & \% & 7 \\
\hline$\% 1 \ldots$ & V & $\%$ \% 0.00 & V & $\% 1 \ldots$ & V & $\% 9 . .91$ & V & $\% 9 . .91$ & V & $\% 1 \ldots$ & V \\
\hline$\% 9 . .91$ & $\Lambda$ & $\% 1 \ldots$ & $\wedge$ & $\% 9 . .91$ & $\wedge$ & $\% 1 \ldots$ & $\wedge$ & $\% 9 . .91$ & $\wedge$ & $\% 9 . .91$ & $\Lambda$ \\
\hline$\% 1 \ldots$ & 9 & $\% 9 . .91$ & 9 & $\% 9 . .91$ & 9 & $\% 1 \ldots$ & 9 & $\% \leqslant 0 . \leqslant 0$ & 9 & $\% 1 \ldots$ & 9 \\
\hline$\% 1 \ldots$ & 1. & $\% 1 \ldots$ & 1. & $\% 9 . .91$ & 1. & \% & 1. & $\% 9 . .91$ & 1. & \%.7. & 1. \\
\hline$\% \wedge 1 . \wedge r$ & 11 & \% VY.VT & 11 & $\% 1 \ldots$ & 11 & $\% \wedge I . \wedge r$ & 11 & $\% 1 \ldots$ & 11 & $\% \wedge 1 . \wedge r$ & 11 \\
\hline \multirow[t]{8}{*}{$\% 0 \leqslant .00$} & Ir & $\% \wedge 1 . \wedge r$ & Ir & $\% 1 \ldots$ & Ir & $\% 9 . .91$ & Ir & $\% 9 . .91$ & ir & $\% \leqslant 0 . \leqslant 0$ & IT \\
\hline & & \% VY.VT & سו & $\% 9 . .91$ & r & $\% 1 \ldots$ & r & $\% 0 \leqslant .00$ & r & $\% 1 \ldots$ & r \\
\hline & & $\% 1 \ldots$ & $1 \varepsilon$ & $\% 0 \leqslant .00$ & $1 \varepsilon$ & $\% \wedge I . \wedge r$ & $1 \varepsilon$ & $\% \wedge I . \wedge r$ & $1 \varepsilon$ & $\% 1 \ldots$ & $1 \leq$ \\
\hline & & $\% 9 . .91$ & 10 & $\% 1 \ldots$ & 10 & $\% \leqslant 0 . \leqslant 0$ & 10 & $\% 9 . .91$ & 10 & $\% 9 . .91$ & 10 \\
\hline & & & & & & $\% 1 \ldots$ & 17 & $\% 1 \ldots$ & 17 & $\% 9 . .91$ & 17 \\
\hline & & & & & & & & $\% 9 . .91$ & IV & $\% 1 \ldots$ & iv \\
\hline & & & & & & & & $\%$ \% . . o & 11 & $\% \leqslant 0 . \leqslant 0$ & 11 \\
\hline & & & & & & & & $\% 1 \ldots$ & 19 & & \\
\hline
\end{tabular}

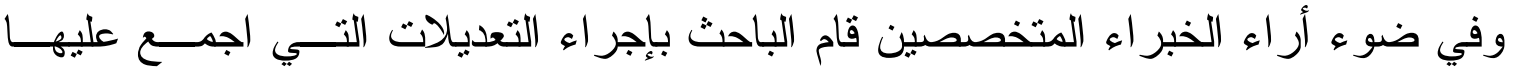

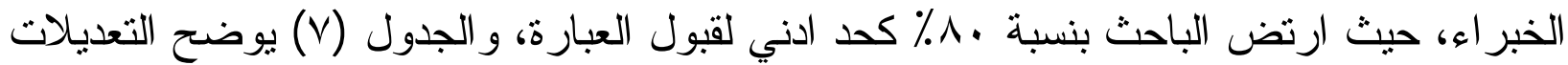
من حيث (الحذف - التعديل - الاضافة) على عدد العبار ات خلال المقياس. 
جدول (V)

عدد العبارات التي تم حذفها أو تعديلها أو إضافتها في المقياس

\begin{tabular}{|c|c|c|c|c|c|c|}
\hline \multirow{2}{*}{ النهائي } & \multicolumn{3}{|c|}{ عدد العبارات } & \multirow{2}{*}{ المبئي } & \multirow{2}{*}{ مسمى المحور } & \multirow{2}{*}{ المحاور } \\
\hline & إضافة & تعديل & حنف & & & \\
\hline ir & - & 1 & 7 & 11 & قيمة الانتماء للفريق & الأول \\
\hline $1 \varepsilon$ & - & r & 0 & 19 & التعاون و المشاركة & الثاني \\
\hline ir & - & 1 & $\varepsilon$ & 17 & تحمل المسئولية & الثالث \\
\hline ir & - & 1 & r & 10 & الاحتر ام & الر ابع ابع \\
\hline ir & - & 1 & r & 10 & الصدق & الخامس \\
\hline$\wedge$ & - & - & $\varepsilon$ & ir & الحرية & السادس \\
\hline$\checkmark$. & - & 7 & ro & 90 & & المجموع \\
\hline
\end{tabular}

يتضح من جدول(V) أن عدد عبار ات المحاور الستة بالترتيب بعد اجر اء التعديلات كالتالي

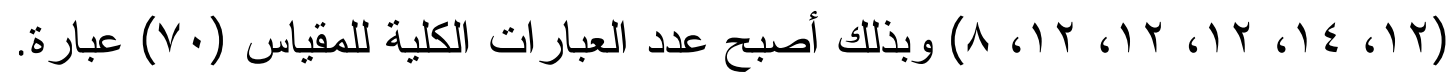

\section{جدول (^)}

العبارات التي تم تعديلها في مقياس القيم الاجتماعية

\begin{tabular}{|c|c|c|}
\hline العبارات بعد التعديل & العبارات قبل التعديل & 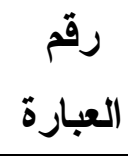 \\
\hline \multicolumn{3}{|c|}{ المحور الاول: قيمة الانتماء للقريق: } \\
\hline 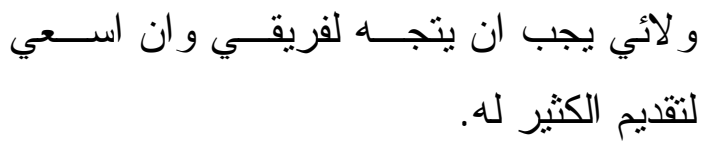 & ولتائي يتجه لفريقي وان اسعي & 1 \\
\hline \multicolumn{3}{|c|}{ المحور الثاني: التعاون والمشاركة: } \\
\hline افض يصعب اتخاذ القرار ات السريعة لمشاكلنا قبل & يصعب حلها القر ار ات لمشـــاكلنا قبــلـ ان & $r$ \\
\hline السعدي جاهدا لإنجاز ما اكلف به مــن قبــل & أقوم بإنجاز ما اكلف به مــن قبــلـ & 17 \\
\hline \multicolumn{3}{|c|}{ المحور الثالث: تحمل المسئولية: } \\
\hline تحملي المسئولية تزيد من انتمائي لفريقي & كلما زاد انتمائي لفريقي زاد تحملي & 0 \\
\hline
\end{tabular}




\section{تابع جدول (1)}

العبارات التي تم تعديلها في مقياس القيم الاجتماعية

\begin{tabular}{|c|c|c|}
\hline العبارات بعد التعديل & العبارات قبل التعديل & العبارة - مقر \\
\hline \multicolumn{3}{|c|}{ المحور الرابع: الاحترام: } \\
\hline الفريق اقدر واحترم خصوصيات زملائـــــداخـلـل & الفريق & 11 \\
\hline \multicolumn{3}{|c|}{ المحور الخامس: الصدق: } \\
\hline 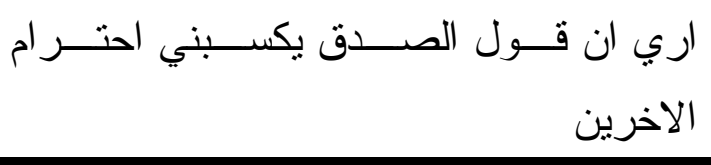 & 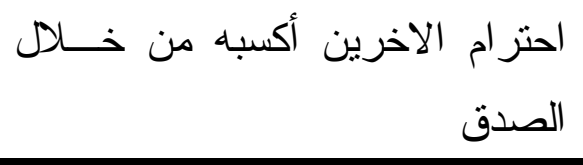 & $1 \leqslant$ \\
\hline
\end{tabular}

يوضح جدول(^) العبارات التي تم تعديلها في مقياس القيم الاجتماعية والتي بلغ

عددهم آعبار ات بواقع عبارة للمحور الاول، وعبارنين للمحور الثاني، وعبارة للمحور الثالث، وعبارة للمحور الرابع، وعبارة للمحور الخامس. وقد تم عرض المقياس في صورته الأولية مرة ثانية على الخبراء في مجال علم الاجتماع و القياس

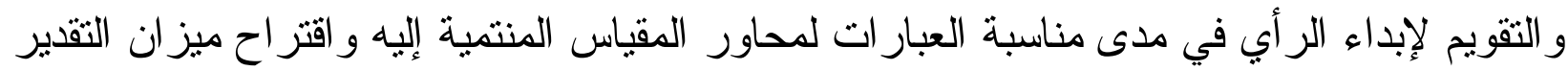
وكانت النتيجة كما يوضحها جدول (9): 


\section{جدول (9)}

التكرارات والنسب المئوية لآراء الخبراء في مفردات مقياس القيم الاجتماعية ن=

\begin{tabular}{|c|c|c|c|c|c|c|c|c|c|c|c|}
\hline المحور & r & الخحور & p & المحور المع & r & المحور & r & المحور & $\hat{r}$ & المحور الأول & r \\
\hline$\% 1 \ldots$ & 1 & $\% 1 \ldots$ & 1 & $\% 1 \ldots$ & 1 & $\% 1 \ldots$ & 1 & $\% 1 \ldots$ & 1 & $\% 9 \cdot .91$ & 1 \\
\hline$\% 9 . .91$ & r & $\% 1 \ldots$ & $r$ & $\% 1 \ldots$ & r & $\% .9 \cdot .91$ & r & $\% 1 \ldots$ & r & $\% 1 \ldots$ & r \\
\hline$\% 1 \ldots$ & r & $\% 9 . .91$ & $r$ & $\% 1 \ldots$ & $r$ & $\%$ & r & $\% 1 \ldots$ & r & $\% 1 \ldots$ & r \\
\hline$\% 1 \ldots$ & $\varepsilon$ & $\% 1 \ldots$ & $\varepsilon$ & $\% .9 . .91$ & $\varepsilon$ & $\% 1 \ldots$ & $\varepsilon$ & $\% 1 \ldots$ & $\varepsilon$ & $\% 9 . .91$ & $\varepsilon$ \\
\hline$\% 1 \ldots$ & 0 & $\%, \ldots$ & 0 & $\% 1 \ldots$ & 0 & $\% 1 \ldots$ & 0 & $\% 9 . .91$ & 0 & $\% 1 \ldots$ & 0 \\
\hline$\% 1 \ldots$ & 7 & $\% 1 \ldots$ & 7 & $\% 9 . .91$ & 7 & $\% 1 \ldots$ & 7 & $\% 1 \ldots$ & 7 & $\% 1 \ldots$ & 7 \\
\hline$\% 1 \ldots$ & V & $\% 1 \ldots$ & V & $\% 1 \ldots$ & V & $\%$ & V & $\% 1 \ldots$ & V & $\% 1 \ldots$ & V \\
\hline \multirow[t]{7}{*}{$\% 1 \ldots$} & $\wedge$ & $\% 1 \ldots$ & $\wedge$ & $\% 1 \ldots$ & $\wedge$ & $\%$ & $\wedge$ & $\% 9 . .91$ & $\wedge$ & $\% 1 \ldots$ & $\wedge$ \\
\hline & & $\% 9 . .91$ & 9 & $\% 1 \ldots$ & 9 & $\%$ & 9 & $\% 1 \ldots$ & 9 & $\% 1 \ldots$ & 9 \\
\hline & & $\% 1 \ldots$ & 1. & $\% 1 \ldots$ & 1. & $\% 1 \ldots$ & 1. & $\%, \ldots$ & 1. & $\% 1 \ldots$ & 1. \\
\hline & & $\% 1 \ldots$ & 11 & $\% 1 \ldots$ & 11 & $\% .9 . .91$ & 11 & $\% 1 \ldots$ & 11 & $\% .9 \cdot .91$ & 11 \\
\hline & & $\%, \ldots$ & Ir & $\% 1 \ldots$ & ir & $\% 1 \ldots$ & IT & $\%, \ldots$ & IT & $\% 1 \ldots$ & IT \\
\hline & & & & & & & & $\% 9 . .91$ & r & & \\
\hline & & & & & & & & $\% 1 \ldots$ & $1 \varepsilon$ & & \\
\hline
\end{tabular}

يتضح من الجدول (9) أن آر اء الخبر اء قد أثنارت إلى قبول جميع عبار ات المقياس حيث تر اوحت .

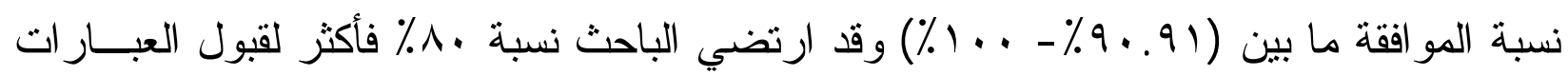
وبذلك أصبح عدد مفردات المقياس ( V. (V) . ميزان التقدير:

استخدم الباحث ميز ان تقدير ثلاثي (مو افق - الي حد ما - غير مو افق) حيث يعبر ذلك عن درجات

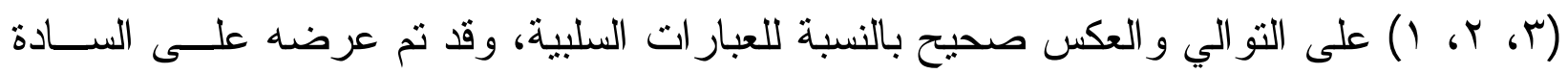

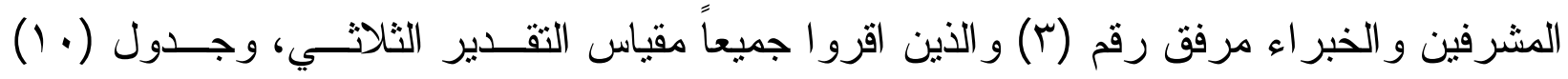
يوضح ار اء الخبر اء حول مقياس التقدير، وتتر اوح الدرجة الكلية للاسنيان في صورنه النهائية من • ا ب درجة كحد أقصى الى • V درجة كحد ادنى. 


\section{جدول (. (1)}

اراء الخبراء حول ميزان تقدير مقياس القيم الاجتماعية

\begin{tabular}{|c|c|c|c|}
\hline النسبة المئوية & التكر ارات & الميزان & م \\
\hline$\% 1 \wedge .11$ & $r$ & ثنائي & 1 \\
\hline \% & 9 & ثلاثي & r \\
\hline
\end{tabular}

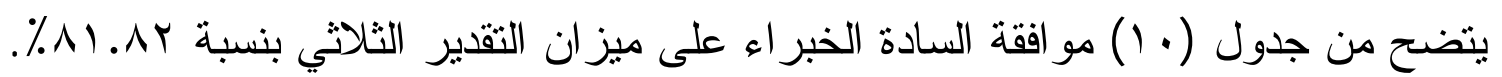
وضع الصورة النهائية للمقياس: في ضو ء ما أبداه الخبر اء من أراء و اقتر احات وبعد أجر اء التعديلات على الصورة المبدئية الاولى الهى

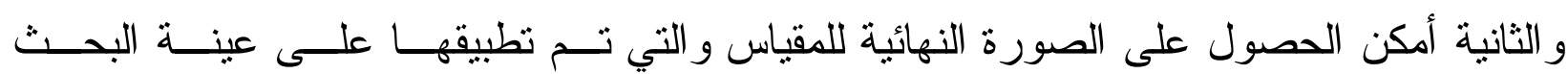

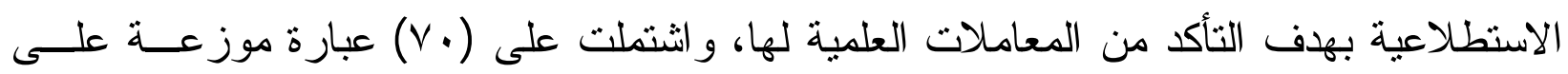

جدول رقم (11)

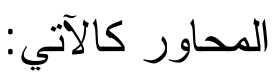
محاور مقياس القيم الاجتماعية النهائية وعدد عبار ات كل محور

\begin{tabular}{|c|c|c|}
\hline عدد العبار ات & المحور & المقياس \\
\hline$\overline{T r}$ & قيمة الاتتماء للفريق. & \\
\hline $1 \varepsilon$ & التعاون و المشاركة. & \\
\hline ir & تحمل المسئولية. & a \\
\hline ir & الاحتر ام. & القيخ الاجنماعية \\
\hline ir & الصدق. & \\
\hline$\Lambda$ & الحريةة & \\
\hline عبارة V. عبار V. & \multicolumn{2}{|l|}{ المجمـوع } \\
\hline
\end{tabular}

حيث قام الباحث بتوزيع عبار ات محاور المقياس عشو ائياً لكى يتم تطبيقـــه علــى افــر اد العينـــة الاستطلاعية لإيجاد المعاملات العلمية للمقياس. تصحيح المقياس:

قام الباحث بتحديد ثلاث درجات لكل إجابة ب "مو افق"، ودرجنين لكل إجابة ب "الــي حــ مــا" ودرجة و احدة لكل اجابة "غير مو اقق" لكل سؤال من أسئلة المقياس، وكان إجمالي درجاته ( • (r) درجة. الار اسة الاستطلاعية:

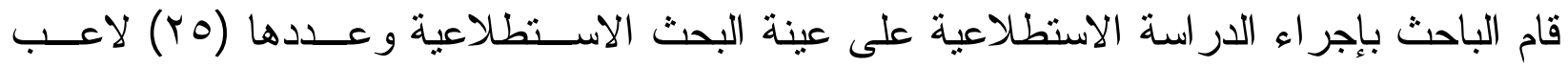
وذللك بهذف التعرف على: 
- الصعوبات التي قد تو اجه الباحث أنثاء تتفيذ الدر اسة الأساسية. - تقهم اللاعبين لعبار ات مقياس القيم الاجتماعية. - التأكد من المعاملات العلمية (الصدق - الثبات) لمقياس القيم الاجتماعية. المعاملات العلمية لأداة البحث (مقياس القيم الاجتماعية):

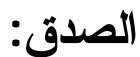

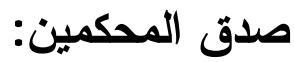
حيث قام الباحث بعرض محاور المقياس و عبار ات كل محور على الخبر اءو وعدهم (1) (1)، و اعتبر الباحث نسبة الاتفاق للخبر اء على المحاور و العبار ات معيار الصدقة.

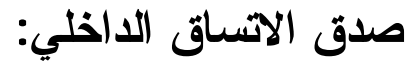
قام الباحث بحساب صدق الاتساق الداخلي بين كل عبارة ودرجة كل محور وبين كل محور و الدرجة الكلية للمقياس، حيث تم تطبيق المقياس على العينة الاستطلاعية وعددهن(ب) لاعب وجدول (1) و يوضح ذلك.

جدول (i )

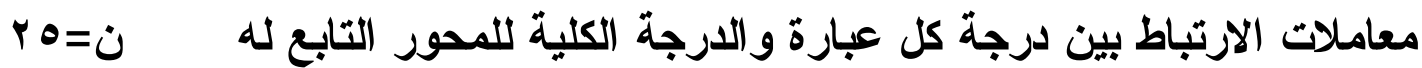

\begin{tabular}{|c|c|c|c|c|c|c|c|c|c|c|c|}
\hline المحور & r & الخحور & P & المحور & r & المحور & r & المحور & r & المحور & r \\
\hline$* .947$ & 1 & $* . . \leqslant \vee 0$ & 1 & $* .790$ & 1 & $* . . V \leq 0$ & 1 & $* .019$ & 1 & $* . \neg \wedge V$ & 1 \\
\hline$* .0 Y \leqslant$ & r & $* .70 \leqslant$ & r & $* . .0 \leqslant V$ & r & $* . \leqslant \wedge 0$ & r & $* .70 \leqslant$ & r & $* .79 \wedge$ & r \\
\hline$* .7 r q$ & r & $* .7 \leq \Lambda$ & $r$ & $* . \vee \vee \leqslant \wedge$ & r & $* .90 \leqslant$ & r & $* . . \wedge \vee 1$ & r & $* .0 \leqslant \Lambda$ & r \\
\hline$* . V_{Y}$ & $\varepsilon$ & *..VYO & $\varepsilon$ & $* . \wedge r l$ & $\varepsilon$ & $* .019$ & $\varepsilon$ & $* . . V \leq 0$ & $\varepsilon$ & $*$. . 70 & $\varepsilon$ \\
\hline * * & 0 & $*$. * \^० & 0 & * . . & 0 & $* . . \leqslant 1 \wedge$ & 0 & *. . TrV & 0 & $*$. . OVᄉ & 0 \\
\hline$* . . \Sigma \vee \wedge$ & 7 & $* . . V \leq r$ & 7 & $* . . \leqslant \wedge 0$ & 7 & $* . .7 \leq V$ & 7 & $* . \wedge 01$ & 7 & *. . Tor & 7 \\
\hline$* . .0 Y$. & V & $* .70 \mathrm{~V}$ & V & $* .007$ & V & $* .0 Y 1$ & V & $* .70 \wedge$ & V & $* . \vee \vee 01$ & V \\
\hline \multirow[t]{7}{*}{$* .79 r$} & $\Lambda$ & $* . . V \leq r$ & $\wedge$ & $* .70 \leqslant$ & $\Lambda$ & *..vor & $\Lambda$ & $* . V \leq 0$ & $\wedge$ & $* .90 \leqslant$ & $\Lambda$ \\
\hline & & ד. * • & 9 & *. . . & 9 & $* .777$ & 9 & $* .791$ & 9 & דוא. . * & 9 \\
\hline & & *..V7 & $1 \cdot$ & $* . . \leqslant \vee 0$ & $1 \cdot$ & $* . V \mid \leq$ & 1. & *..vol & 1. & $* . V \leq 0$ & 1 . \\
\hline & & $*$. * T人० & 11 & $* . .7 \vee \leqslant$ & 11 & $* . . T V Y$ & 11 & *..TYו & 11 & $* . \leqslant \wedge 0$ & 11 \\
\hline & & $* . .0 \leqslant 1$ & Ir & $* .779$ & Ir & $* .70 \wedge$ & ir & $* . .0 \leqslant V$ & ir & $* . \wedge \vee \leqslant$ & Ir \\
\hline & & & & & & & & $* . .7 V 1$ & $1 T$ & & \\
\hline & & & & & & & & $* . . V \leqslant 1$ & $1 \varepsilon$ & & \\
\hline
\end{tabular}




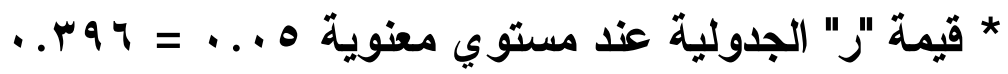

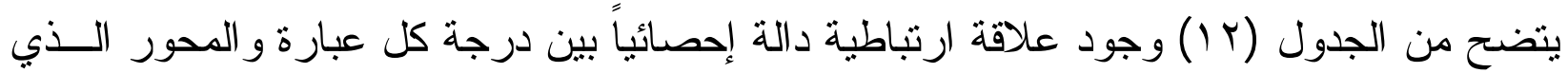
تتنمي إليه العبارة مما يثير إلى دلالة جميع معاملات الارنباط بين كل عبارة وبين درجة المحور

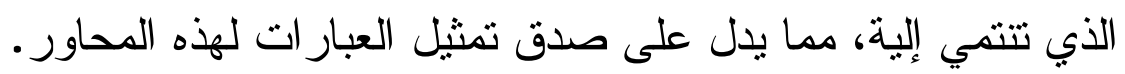

جدول(r 1 (1)

معاملات الارتباط بين محاور المقياس

\begin{tabular}{|c|c|c|c|c|c|c|}
\hline الحرية & الصدق & الاحتر ام & المسئولية & التعاون والمشاركة & قيمة الاتتماء للفريق & المحور \\
\hline$* . . \vee \leqslant 1$ & *. . TAr & $* . .099$ & $* . .0 V \varepsilon$ & $* . .7 \leq \wedge$ & & قيمة الانتماء للفريق \\
\hline *..T4T & $* . . \wedge 1$. & $*$. . $>$ q & $* . .701$ & & & التعاون و المشاركة \\
\hline$* . .0 \mathrm{Vo}$ & $* . .0 \mathrm{VV}$ & $* . .749$ & & & & تحمل المسئولية \\
\hline$* .707$ & $* . .719$ & & & & & الاحتر ام \\
\hline \multirow[t]{2}{*}{$* .779$} & & & & & & الصدق \\
\hline & & & & & & الحرية \\
\hline
\end{tabular}

* قيمة "ر" الجدولية عند مستوى دلالة ه ... =

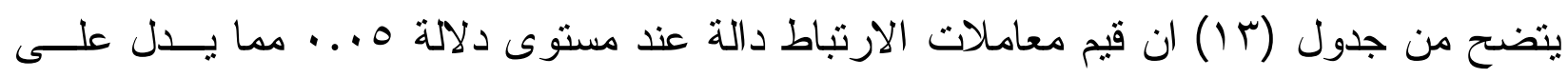
وجود اتساق داخلي بين محاور مقياس القيم الاجتماعية. جدول (؛ (1)

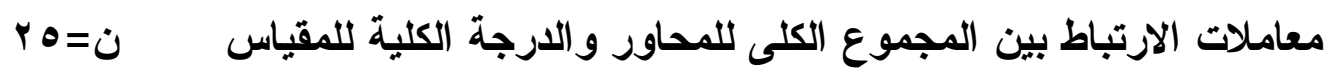

\begin{tabular}{|c|c|c|}
\hline معامل الارتباط & المحور & عدد العبارات \\
\hline$* . .70 \leqslant$ & قيمة الاتتماء للفريق & ir \\
\hline$* . .0 \leqslant 1$ & |النعاون و المشاركة & $1 \varepsilon$ \\
\hline$* . . V \leqslant \Lambda$ & | تحمل المسئولية & ir \\
\hline$* . .009$ & | الاحتر ام & ir \\
\hline *..7Tा & | الصدق & ir \\
\hline *..VYO & | الحرية & $\wedge$ \\
\hline
\end{tabular}

قيمة "ر" الجدولية عند مستوى دلالة م. ...=

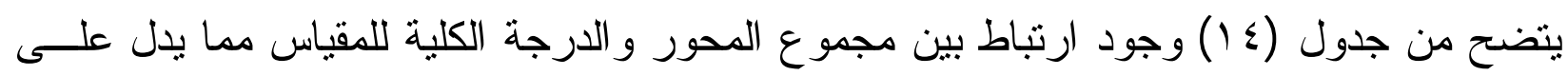
اتساقها الداخلي ومن ثم صدق المقياس. 
(الثباث:

قام الباحث بحساب الثبات باستخدام معامل الفا كرونباخ للاتساق الداخلي بـين المحــاور، ويعد معامل الفا كرونباخ الثكل الاكثر شيوعاً لاختبار معامل ثبات الاتساق الداخلي، وتتر اوح قيم معامل الفا كرونباخ بين : 1 بحيث يثير واحد الى ارنباط مرتفع بين المحاور في حين ان القيمة صفر تشير الى عدم وجود ارتباط بين المحاور، وتشير المر اجع العلمية الى عدم وجــود معيـار يجمع عليه العلماء بما يتعلق بالحد الأدنى لقيمة الفا كرونباخ حتي تكون مقبولة، ولكن غالباً معظم

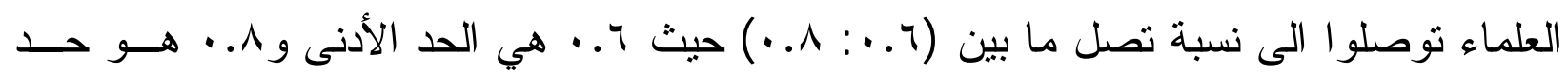
جيد، وفيما يتعلق بمقياس القيم الاجتماعية بين محاور ها وصلت الي (1 ( . ) وتشير هذه النتيجــة الى ثبات مقياس القيم الاجتماعية.

\section{جدول (10)}

معامل الفا كرونباخ لقياس ثبات مقياس القيم الاجتماعية

\begin{tabular}{|c|c|c|}
\hline معامل القا كرونباخ & التجزئة التصفية & المحاور \\
\hline$\cdot . \wedge \leq 1$ &.$\wedge \wedge 0$ & قيمة الانتماء للفريق \\
\hline.$v 09$ & $\cdot . \wedge \vee \wedge$ & التعاون و المشاركة \\
\hline.$V T \varepsilon$ &.$\vee \vee 71$ & تحمل المسئولية \\
\hline .794 & ש . & الاحتر ام \\
\hline.$\wedge \wedge$. &.$\wedge V \vee$ & الصدق \\
\hline ס ט &.$V 17$ & الحرية \\
\hline.$A T V$ & 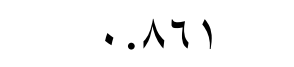 & درجة المقياس الكلية \\
\hline
\end{tabular}

ويتضح من جدول (10) أن معاملات الثبات بالتجزئة النصفية لمحاور المقياس تز اوحــت

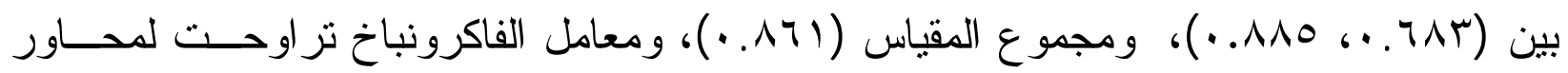

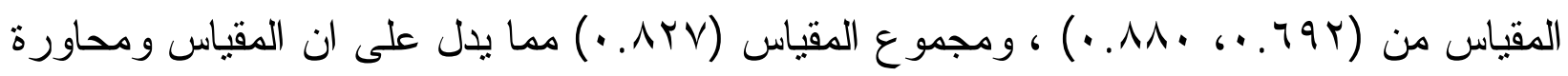
ذو معامل ثبات عالي . الار اسة الاسساسبة: قام الباحث بمخاطبة نادي الثرقية الرياضي بخطاب رسمي من كلية التربية الرياضبة للبنين جامعة الزفازيق مرفق رقم (7) لتسهيل عملية إجراء تطبيق اجر اءات البحث حيث قام الباحث 


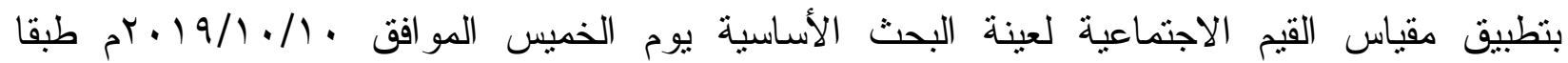
للمو اصفات و الثروط الخاصة بتطبيق المقياس وكذلك القائمين بعملية القياس وبحضور السادة المشرفين.

$$
\text { وقد ر اعي الباحث قبل تطبيق المقياس ما يلي: }
$$

$$
\text { - إعطاء شرح و افي لطريقة الاجابة علي عبار ات المقياس . }
$$

\section{المعالجات الإحصائية:}

تم استخدام المعالجات الإحصائية المناسبة لطبيعة البحث وذللك باستخدام برنامج (Excel) لإدخال

$$
\begin{aligned}
& \text { البيانات و البرنامج الإحصائي (Spss) لإجر اء العمليات الإحصائية للبحث . }
\end{aligned}
$$

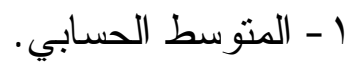

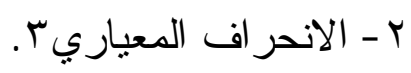

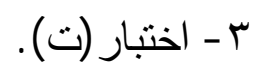

$$
\begin{aligned}
& \text { ـ - تحليل التباين باستخدام اختبار (ف). } \\
& \text { o - معامل الفاكرونباخ. }
\end{aligned}
$$

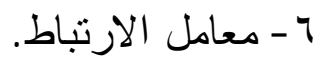

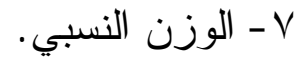

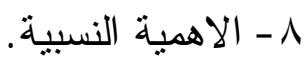

$$
\begin{aligned}
& 9 \text { - قيمة كك. }
\end{aligned}
$$




\section{مرض النتائج ومناقشتها:}

\section{عرض النتائج:}

\section{جدول (1 1 )}

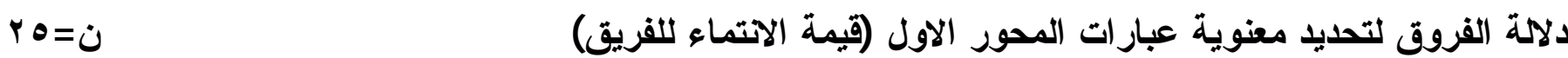

\begin{tabular}{|c|c|c|c|c|c|c|c|c|c|c|c|}
\hline \multirow{2}{*}{ الترتيب } & \multirow{2}{*}{ 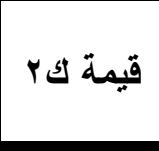 } & \multirow{2}{*}{ الاهمية } & \multirow{2}{*}{ النسبن } & \multicolumn{2}{|c|}{ 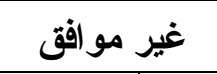 } & \multicolumn{2}{|c|}{ الى حـ ما } & \multicolumn{2}{|c|}{ 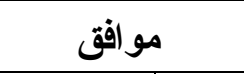 } & \multirow{2}{*}{ عبار ات المحور } & \multirow{2}{*}{ b } \\
\hline & & & & $\%$ & ك & $\%$ & ك & $\%$ & S & & \\
\hline o & *ro.. & $94 . .$. & 79 & $\varepsilon \ldots$ & 1 & $17 .$. & $\varepsilon$ & A... & $r \cdot$ & و لائي يجب ان يتجه لفريقي وان اسعي لنقديم الكثير له & 1 \\
\hline r & *rq.1r & ar.4r & $\checkmark \cdot$ & $\varepsilon \ldots$ & 1 & Ir... & $r$ & $\wedge \leq \ldots$ & $r_{1}$ & انتمائي لفريقي وتمسكي به دعامة اساسية للفوز وتحقيق الاهداف & r \\
\hline 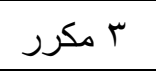 & $*$ * $9.1 r$ & ar.r & $v \cdot$ & $\varepsilon \ldots$ & 1 & ir... & $r$ & $\wedge \varepsilon \ldots$ & r) & حرصي الثديد علي فوز فريقي يزيد من انتمائي له & $r$ \\
\hline r & *r人.VY & $97 . .$. & VY & $\varepsilon \ldots$ & 1 & $\varepsilon \ldots$ & 1 & qr... & r & اسعي دائما للفوز وتحقيق اهداف فريقي & $\varepsilon$ \\
\hline 1 & $*$ *1.17 & $91.7 \mathrm{~V}$ & $V \varepsilon$ & $\cdots$ & $\cdot$ & $\varepsilon \ldots$ & 1 & $97 . .$. & $r \varepsilon$ & انتمائي لفريقي يزيد من احتر امي لذاتي & 0 \\
\hline 1 & $*$ * I. $\varepsilon \varepsilon$ & $9 . .7 V$ & 71 & $\varepsilon \ldots$ & 1 & $r \cdot \ldots$ & 0 & vч... & 19 & الانتماء للفريق بزيد من التماسك بين اعضاء الفريق & 1 \\
\hline $1 \cdot$ & $* 1 \leq . \leq \wedge$ & ᄉ..TV & 70 & ^... & $r$ & $r \varepsilon \ldots$ & 7 & T1... & iv & احب مشاركة زملائي في الفريق افر احهم واحز انهم & $\mathrm{V}$ \\
\hline ir & $* \wedge . r \varepsilon$ & 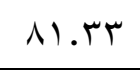 & 1) & $17 .$. & $\varepsilon$ & $r \varepsilon \ldots$ & 7 & $7 \ldots$ & 10 & انتمائي لفريقي بساعدني علي نطوير نفسي & $\wedge$ \\
\hline 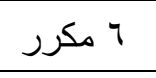 & $*$ * I. $\leq \varepsilon$ & $9 . .7 \mathrm{~V}$ & 71 & $\varepsilon \ldots$ & 1 & $r \ldots$ & 0 & v ... & 19 & الانتماء للفريق يزيد من التزابط و العلاقات بين افراد الفريق & 9 \\
\hline 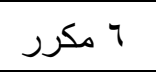 & $* Y \leq .07$ & $9 . .7 \mathrm{~V}$ & 71 & $\wedge . \cdots$ & r & r... & r & $\wedge \ldots$ & $r \cdot$ & يكسبني انتمائي لفريقي احتر ام الاخرين & 1. \\
\hline 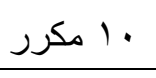 & $* 17 . \wedge 1$ & $\wedge 7.7 \mathrm{~V}$ & 70 & ir... & $r$ & $17 .$. & $\varepsilon$ & $V r \ldots$ & 11 & الانتماء يعني ارتباط روح وجسد اللاعب لفريقة & 11 \\
\hline 9 & * & Qצ.M & TV & $\varepsilon \ldots$ & 1 & ^... & r & $\wedge \wedge .$. & rt & احب مساعدة زملائي داخل الفريق & ir \\
\hline
\end{tabular}




\section{جدول (iv)}

rovi

دلالة الفروق لتحديد معنوية عبارات المحور الثاني (التعاون والمشاركة)

\begin{tabular}{|c|c|c|c|c|c|c|c|c|c|c|c|}
\hline \multirow{2}{*}{ الترتيب } & \multirow{2}{*}{ قيمة كو } & \multirow{2}{*}{ الالهمبة } & \multirow{2}{*}{ الوزن } & \multicolumn{2}{|c|}{ 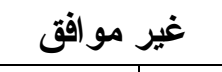 } & \multicolumn{2}{|c|}{ 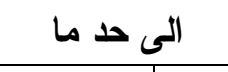 } & \multicolumn{2}{|c|}{ 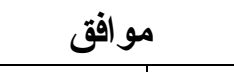 } & \multirow{2}{*}{ عبار ات المحور } & \multirow{2}{*}{ b } \\
\hline & & & & $\%$ & ك & $\%$ & ك5 & $\%$ & 5 & & \\
\hline 7 & $* 1 \leq . \leq \Lambda$ & งา. $.7 \mathrm{~V}$ & 70 & А... & r & $r \varepsilon \ldots$ & 7 & $7 \wedge .$. & iv & احب القيام بالأعمال المشتركة مع زملائي في الفريق & 1 \\
\hline 9 & 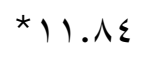 & 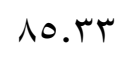 & $7 \varepsilon$ & $\varepsilon \ldots$ & 1 & 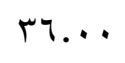 & 9 & $7 \ldots$ & 10 & افضل اتخاذ القرار ات السريعة لمشاكلنا قبل ان بصعب حلها & r \\
\hline r & 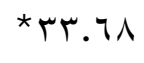 & $9 \leq .7 V$ & $v_{1}$ & $\varepsilon \ldots$ & 1 & ᄉ... & r & $\wedge \wedge .$. & rt & افضل ان يتولى شخص و احد قيادة الفريق & r \\
\hline 1. & $* \wedge . \Upsilon \leq$ & 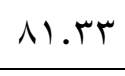 & 71 & $7 \ldots$ & 10 & $r \varepsilon \ldots$ & 7 & $17 . \ldots$ & $\varepsilon$ & احب العمل و التدريب بمفردي بدلا من العمل مع الاخرين & $\varepsilon$ \\
\hline 1 & $* 1 \vee .7 \leq$ & 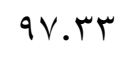 & r & $\cdots$ & $\cdot$ & ᄉ... & r & $9 q_{.} .$. & r & اشارك زملائي في الفريق المناسبات الشخصية والاجتماعية & 0 \\
\hline 1. & *V.r^ & 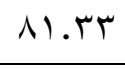 & $7)$ & Ir... & r & 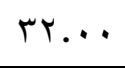 & $\wedge$ & $07 .$. & $1 \varepsilon$ & افضل المشاركة في صنع القرار ات & 7 \\
\hline 0 & $*$ Y I. $\varepsilon \varepsilon$ & $9 . .7 V$ & 71 & $\varepsilon \ldots$ & 1 & $r \cdot \ldots$ & 0 & $\vee 7 .$. & 19 & مشاركتي في صنع القرار ات تزيد من قدرتي علي تحمل المسئولية & $\checkmark$ \\
\hline 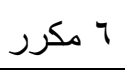 & * H.or & งᄀ. & 70 & $\varepsilon \ldots$ & 1 & r.... & $\wedge$ & $7 \leq \ldots$ & 17 & أرحب بقضاء وقت الفر اغ مع زملائي في الفريق & $\Lambda$ \\
\hline $1 \varepsilon$ & $* \wedge . \vee Y$ & 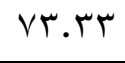 & 00 & $07 .$. & $1 \varepsilon$ & А... & r & พч... & 9 & افضل العمل بمفردي حتي اظهر نفسي داخل الفريق & 9 \\
\hline 14 & *IT.Y & $V \leq .7 V$ & 07 & $r \ldots$ & 0 & 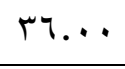 & 9 & $\varepsilon \varepsilon \ldots$ & 11 & اشعر ان مشاكل الفريق مشاكل شخصية بالنسبة لي & $1 \cdot$ \\
\hline it & 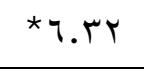 & $\wedge \ldots$ & 7. & $17 .$. & $\varepsilon$ & r^... & V & 07... & $1 \leq$ & تحقيق اهداف الفريق مسئولية جماعية & 11 \\
\hline$r$ & $* q \ldots$ & 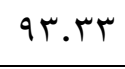 & V. & $\cdots$ & $\cdot$ & $r \ldots$ & 0 & $\wedge \cdot \ldots$ & $r \cdot$ & اسعي جاهدا لإنجاز ما اكلف به من قبل المدرب & ir \\
\hline 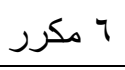 & $* r . . v r$ & ง . . V & 70 & $17 .$. & $\varepsilon$ & $\wedge . \cdots$ & $r$ & V $1 .$. & 19 & الفوز ليست مسئولية الفريق فقط & 14 \\
\hline$\varepsilon$ & *Yo.. $\varepsilon$ & $9 r \ldots$ & 79 & $\varepsilon \ldots$ & 1 & $17 . \cdots$ & $\varepsilon$ & $\wedge \cdot \ldots$ & $r \cdot$ & احب تكوين صداقات مع الزملاء الجدد داخل الفريق & $1 \varepsilon$ \\
\hline
\end{tabular}

* قيمة كاب عند مستوي معنوية هـ .. . 


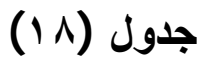

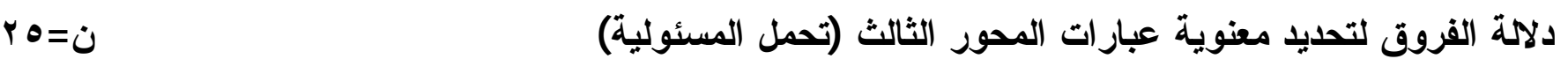

\begin{tabular}{|c|c|c|c|c|c|c|c|c|c|c|c|}
\hline الترتيب & قيمة كو & الاهمبة & النسبن & \multicolumn{2}{|c|}{ غير موافق } & \multicolumn{2}{|c|}{ الى حد ما } & \multicolumn{2}{|c|}{ 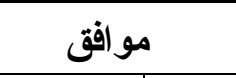 } & عبار ات المحور & p \\
\hline r & $* 1 \vee .7 \leq$ & aV.ru & vr & $\cdots$ & $\cdot$ & $\wedge .$. & r & $94 . .$. & r & اري ان تحمل المسئولية اهم اسباب النجاح و الفوز & 1 \\
\hline 1 & $*$ *1.17 & $91.7 \vee$ & $v \varepsilon$ & $\cdots$ & $\cdot$ & $\varepsilon \ldots$ & 1 & $97 .$. & $r \varepsilon$ & يجب ان يتحلى اعضاء الفريق بقدر كبير من تحمل المسئولية & r \\
\hline 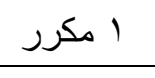 & *r1.17 & $91.7 \vee$ & $V \varepsilon$ & $\cdots$ & $\cdot$ & $\varepsilon \ldots$ & 1 & $97 .$. & $r \leq$ & التخطيط السليم اهم اسباب النجاح & $r$ \\
\hline ir & $* \wedge . \vee r$ & Ar.TV & Tr & А... & $r$ & r... ( ) & 9 & $07 . .$. & $1 \leqslant$ & افضل مشاركة مدربي مشاكل الفريق & 7 \\
\hline 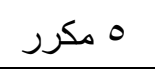 & *ฯ.Vฯ & $94 . .$. & 79 & $\cdots$ & $\cdot$ & $r \varepsilon \ldots$ & 7 & Vฯ.. & 19 & لا ابخل في تقديم المساعدة و النصيحة لزملائي & v \\
\hline$\wedge$ & $* 10.71$ & $\wedge \wedge .$. & 77 & $\varepsilon \ldots$ & 1 & r^... & V & $71 .$. & iv & أثشعر بتحمل المسئولية كأحد أعضاء الجماعة & $\wedge$ \\
\hline 1. & $* 1 . .17$ & $\wedge \varepsilon \ldots$ & 4 & $\wedge . \cdots$ & r & r... & $\wedge$ & $7 \ldots$ & 10 & أعمل جاهدا للمحافظة علي تماسك جماعة فريقي & 9 \\
\hline
\end{tabular}




\section{جدول (19)}

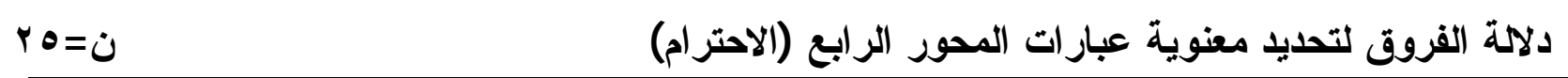

\begin{tabular}{|c|c|c|c|c|c|c|c|c|c|c|c|}
\hline \multirow{2}{*}{ الترتيب } & \multirow{2}{*}{ قيمة ك ت } & \multirow{2}{*}{ الاهمبية } & \multirow{2}{*}{ النسبي } & \multicolumn{2}{|c|}{ غير موافق } & \multicolumn{2}{|c|}{ الى حـ ما } & \multicolumn{2}{|c|}{ 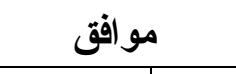 } & \multirow{2}{*}{ عبارات المحور } & \multirow{2}{*}{ r } \\
\hline & & & & $\%$ & ك & $\%$ & ك & $\%$ & S & & \\
\hline r & $* 11.07$ & $9 \leq .7 V$ & v) & $\cdots$ & · & $17 .$. & $\varepsilon$ & $\wedge \varepsilon \ldots$ & r) & افضل الاحتر ام المنبادل بين اعضاء الفريق & 1 \\
\hline 1 & $* Y 1.17$ & $91.7 \mathrm{~V}$ & $V \varepsilon$ & $\cdots$ & . & $\varepsilon \ldots$ & 1 & $97 . .$. & $r \varepsilon$ & احب ان يعاملني مدربي باحتر ام & r \\
\hline r & $* 1 \leq . \leq \varepsilon$ & $97 .$. & VT & $\cdots$ & . & Ir... & $r$ & $\wedge \wedge .$. & rt & التزم و احترم قرارات المسئولين عن الفريق & $r$ \\
\hline v & $* r \cdot . V r$ & Na.ru & TV & ^... & r & $17 .$. & $\varepsilon$ & vч... & 19 & افضل تتفيذ نوجهات مدربي علي اكمل وجه & $\varepsilon$ \\
\hline 7 & $*$ * I. $\varepsilon \varepsilon$ & $9 . .7 \mathrm{~V}$ & 71 & $\varepsilon \ldots$ & 1 & $r \ldots$ & o & v... & 19 & ابدا باحتر ام الاخرين & 0 \\
\hline 1. & $* 1 \leq . \leq \Lambda$ & 人ร. & 10 & $\wedge .$. & r & $r \varepsilon \ldots$ & 7 & $71 .$. & iv & اؤمن تماما بمقولة "عامل الناس كما تحب ان يعاملوك" & 7 \\
\hline$\varepsilon$ & $* q \ldots$ & 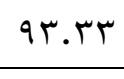 & $v$. & $\cdots$ & . & $r \ldots$ & 0 & $\wedge \ldots$ & $r$. & احتر ام زملائي و اجب تجاهي & V \\
\hline 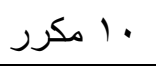 & $* i r . o r$ & 14. $7 \mathrm{~V}$ & 70 & $\varepsilon \ldots$ & 1 & r... & $\wedge$ & $7 \varepsilon \ldots$ & 17 & احتر امي للأخرين يعطي انطباعا حسنا عني & $\wedge$ \\
\hline 9 & $* 10.71$ & м... & 77 & $\varepsilon \ldots$ & 1 & rᄉ... & v & ז1... & iv & اقدر واحترم خصوصيات زملائي داخل الفريق & 9 \\
\hline ir & $* 1 \Gamma . \leq \varepsilon$ & Vฯ... & ov & $17 .$. & $\varepsilon$ & $\varepsilon \cdots$ & 1. & $\varepsilon \varepsilon \ldots$ & 11 & اري ان احتر امي لزملائي يكسبني محبتهم & 1. \\
\hline 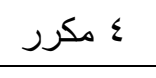 & $* q \ldots$ & 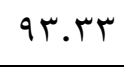 & $\checkmark \cdot$ & $\cdots$ & . & $r \cdot \ldots$ & 0 & $\wedge \cdot \ldots$ & r. & احترم قرار ات مدربي حتي ان اختلفت معه & 11 \\
\hline 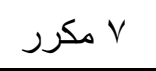 & *in.rr & Na.r & TV & $\varepsilon \ldots$ & 1 & $r \leq \ldots$ & 7 & VY... & 11 & اؤمن بمقولة "احترم حتي ان لم تحب" & ir \\
\hline
\end{tabular}




\section{جدول (r)}

ro=v

دلالة الفروق لتحديد معنوية عبار ات المحور الخامس (الصدق)

\begin{tabular}{|c|c|c|c|c|c|c|c|c|c|c|c|}
\hline \multirow{2}{*}{ الترتيب } & \multirow{2}{*}{ قيمة كوب } & \multirow{2}{*}{ الاهمبية } & \multirow{2}{*}{ النسبي } & \multicolumn{2}{|c|}{ غير موافق } & \multicolumn{2}{|c|}{ الى حـ ما } & \multicolumn{2}{|c|}{ 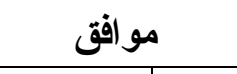 } & \multirow{2}{*}{ عبارات المحور } & \multirow{2}{*}{ b } \\
\hline & & & & $\%$ & ك & $\%$ & ك & $\%$ & S & & \\
\hline r & $* 1 \leq . \leq \varepsilon$ & $97 . .$. & VT & $\cdots$ & $\cdot$ & Ir... & $r$ & $\wedge \wedge .$. & rt & احب ان اكون صادق مع الاخرين داخل جماعة فريقي & 1 \\
\hline$\varepsilon$ & $* 11.07$ & $9 \leq .7 V$ & $v_{1}$ & $\cdots$ & $\cdot$ & $17 .$. & $\varepsilon$ & $\wedge \varepsilon \ldots$ & Y) & أقول الحق دون مجاملة لاحد & r \\
\hline$\wedge$ & $* \wedge . \Upsilon \leq$ & 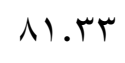 & 71 & $17 .$. & $\varepsilon$ & $r \varepsilon \ldots$ & 1 & $7 . .$. & 10 & قول الصدق احيانا يوقعني في كثير من المشاكل مع الاخرين & r \\
\hline$v$ & $*$ *I. $\leq \varepsilon$ & $9 . .7 \mathrm{~V}$ & $7 \wedge$ & $\varepsilon \ldots$ & 1 & $r \ldots$ & 0 & v ... & 19 & قول الصدق يجعلني راضي تماما عن نفسي & $\varepsilon$ \\
\hline ir & $* I r . r \leq$ & $01.7 \mathrm{~V}$ & $\varepsilon \varepsilon$ & $\leqslant \varepsilon \ldots$ & 11 & r.... & 9 & $r \ldots$ & 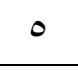 & اري ان الكذب في بعض الاحيان طريقة لتحقيق هدفي & 0 \\
\hline 1 & $* Y 1.17$ & $91.7 \mathrm{~V}$ & $v \varepsilon$ & $\cdots$ & $\cdot$ & $\varepsilon \ldots$ & 1 & $97 .$. & $r \leq$ & احب الصدق في القول و الفعل & 7 \\
\hline 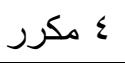 & 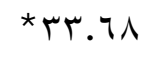 & $9 \leq .7 V$ & v) & $\varepsilon \ldots$ & 1 & ^... & r & $\wedge \wedge .$. & rr & الصدق اقصر الطرق لتحقيق الهدف & V \\
\hline $1 \cdot$ & $* \wedge . \vee r$ & VT.RT & 00 & $07 . .$. & $1 \leq$ & ^... & r & r.... & 9 & اللاعب الذي يتجمل بالكذب يحقق ما يريده بسهولة & $\wedge$ \\
\hline 11 & $* 1 \Gamma . \varepsilon \varepsilon$ & T0.M & $\varepsilon 9$ & $\varepsilon \cdots$ & 1. & $17 .$. & $\varepsilon$ & $\varepsilon \varepsilon \ldots$ & 11 & قول الصدق بسبب لي مشاكل كثيره مع مدربي & 9 \\
\hline 9 & $* 11 . \wedge \varepsilon$ & $V \leqslant .7 V$ & 07 & $7 \ldots$ & 10 & $\varepsilon \ldots$ & 1 & r... & 9 & قول الصدق دائما ما يضر بصاحبة & 1. \\
\hline r & $* 1 \vee .7 \leq$ & QV.rT & vr & $\cdots$ & $\cdot$ & ^... & r & $9 r . .$. & r & اري ان قول الصدق يكسبني احتر ام الاخرين & 11 \\
\hline 7 & *ro.. $\varepsilon$ & $q$ q.... & 79 & $\varepsilon \ldots$ & 1 & $17 .$. & $\varepsilon$ & $\wedge \ldots$ & $r \cdot$ & صدق اللاعب مع نفسه يساعده علي النجاح و النطور & Ir \\
\hline
\end{tabular}




\section{جدول (r)}

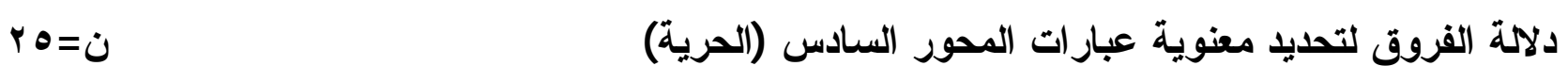

\begin{tabular}{|c|c|c|c|c|c|c|c|c|c|c|c|}
\hline الترتيب & 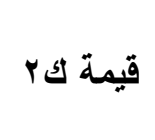 & الاهمبية & النسبب & \multicolumn{2}{|c|}{ غير موافق } & \multicolumn{2}{|c|}{ 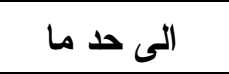 } & \multicolumn{2}{|c|}{ 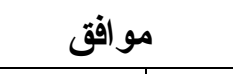 } & عبار ات المحور & p \\
\hline 1 & $* \mid V . T \varepsilon$ & QV.r & vr & $\cdots$ & . & ^... & $r$ & qr... & r & | احب التعبير عن ر ايي داخل الفريق بحرية & 1 \\
\hline 1 & $* \wedge . \vee r$ & NT.TV & $4 r$ & $07 . .$. & $1 \varepsilon$ & r.... & 9 & A... & r & |ؤمن تمام بمقولة "حريتي تتنهي عندما تندا حرية الاخرين" & r \\
\hline v & $* \vee . \vee \uparrow$ & NI.ru & 71 & or... & 14 & $\varepsilon \ldots$ & 1. & А... & r & سياسة الخضوع الكلي للمدرب نؤثر بالسلب و الجمود & $r$ \\
\hline r & $*$ * $9.1 r$ & qu.ru & $\vee \cdot$ & $\varepsilon \ldots$ & 1 & Ir... & $r$ & $\wedge \leq \ldots$ & r) & الحرية دصدر طاقة و الهام للفرد داخل الفريق & 1 \\
\hline$\Lambda$ & $* \uparrow . \wedge \wedge$ & $0 \leq .7 V$ & $\varepsilon$ & $17 .$. & $\varepsilon$ & r... & $\wedge$ & or... & IT & | اشعر احيانا بعدم القدرة علي ابداء الراي & $\mathrm{V}$ \\
\hline r & $* 1 \leq . \leq \varepsilon$ & $97 . .$. & Vr & $\cdots$ & . & Ir... & $r$ & $\wedge \wedge .$. & rt & | الحرية لا تعني عدم احتر ام الاخرين & $\wedge$ \\
\hline
\end{tabular}




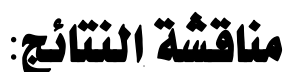

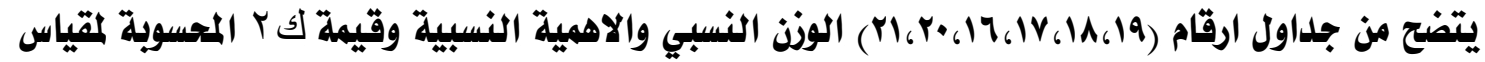

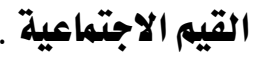

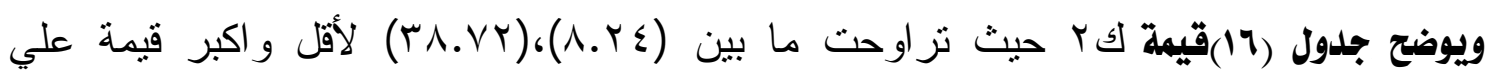

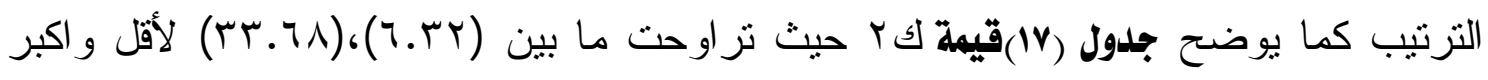

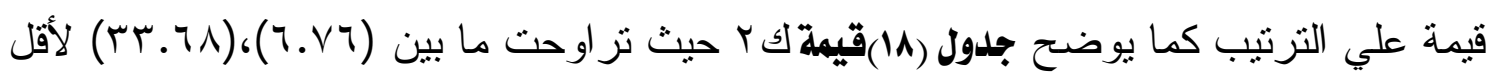

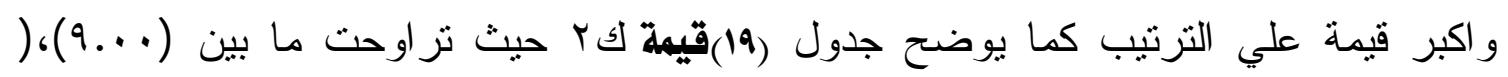

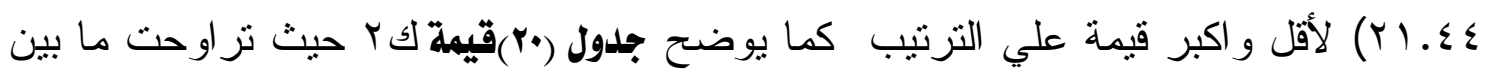

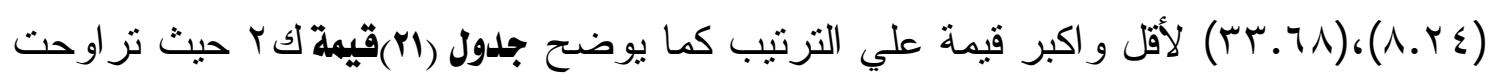

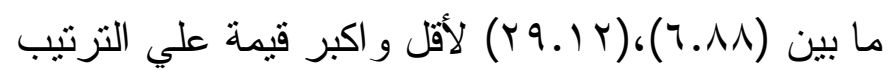

ونستخلص من نتائج مقياس القيم الاجتماعية اعلي قيمة و اقل قيمة لجميع عبار ات المقياس

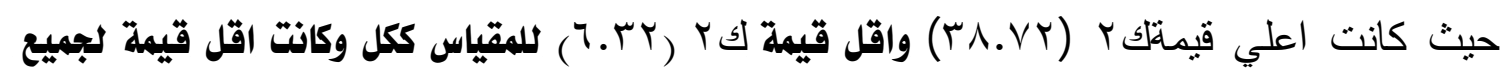

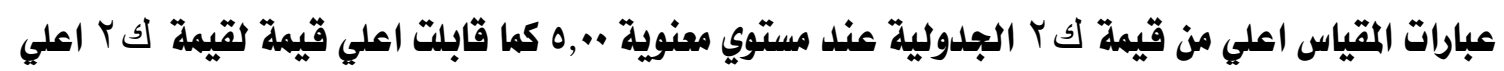

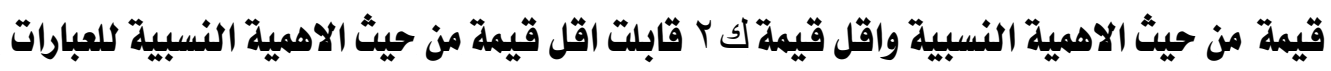

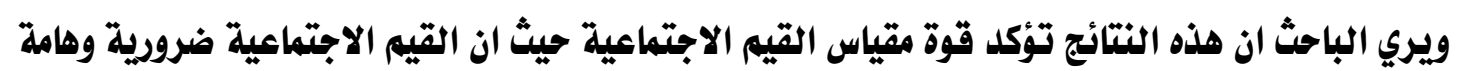

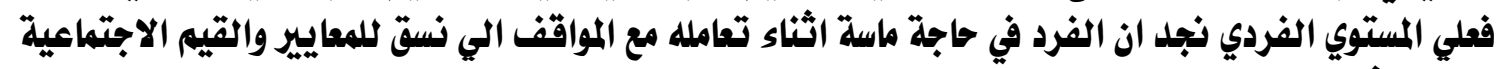

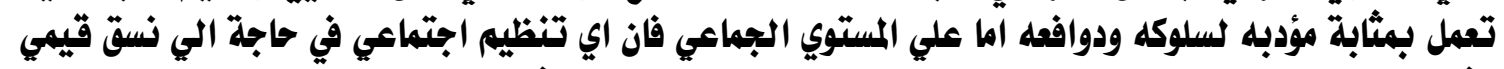

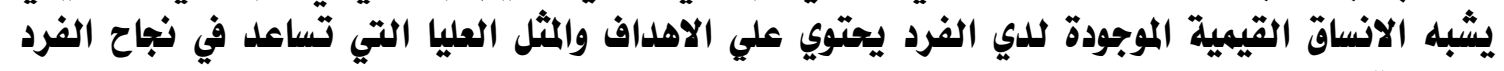
والجماعة.

وفي هذا الصدد اثثار الحسني سعيد علي † +. بم ان القيم الاجتماعية تعد احد المعايير

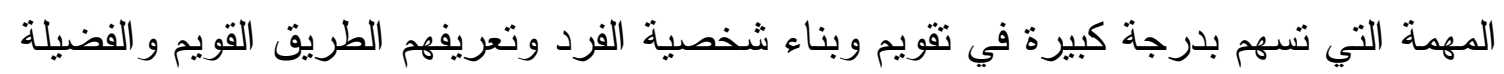

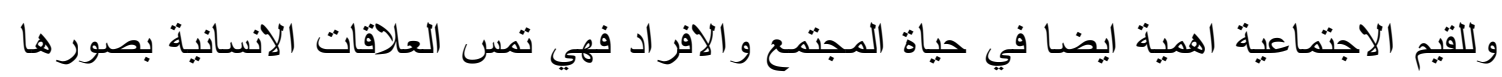

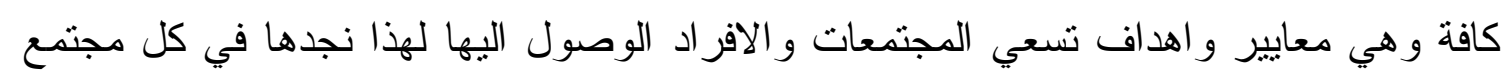
(l V: (1) من المجتمعات

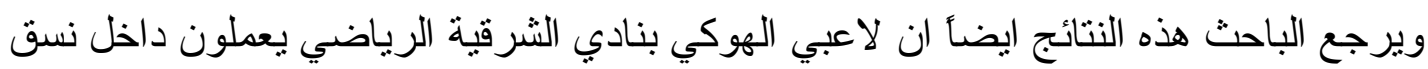

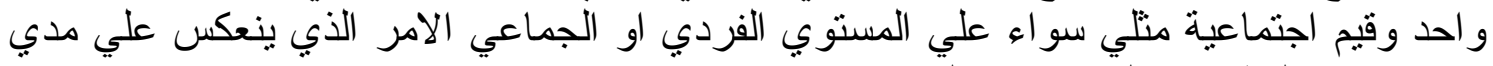
الانجاز ات و البطو لات التي يحققها الفريق. 


\section{الاستخلاصات والتوصيات:}

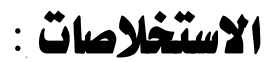

في ضوء مشكلة البحث وأهداف وتساؤلات البحث و العينة المستخذمة والمعالجات الاحصائية و النتائج التي توصل اليها الباحث تم التوصل الي الاستخلاصات الأنية: أ - تم التوصل الي أبعاد مقياس القيم الاجتماعية للاعبي الهوكي.

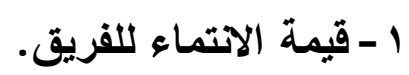

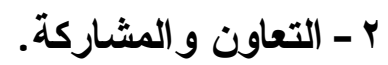

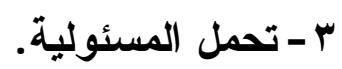

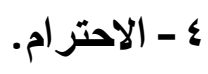

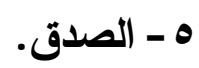

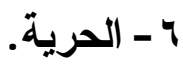

ب -تم التوصل الي قياس مستوي القيم الاجتماعية للاعبي الهوكي.

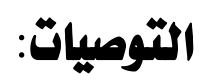

في ضوء نتائج الاراسة والاستتناجات يوصي الباحث بما يلي:

1 - استخام المدربين في قطاعات مصر المختلفة لمقياس القيم الاجتماعية وتطبيقها من حين

$$
\text { لأخر علي اللاعبين للوقوف علي تطور القيم الاجتماعية. }
$$

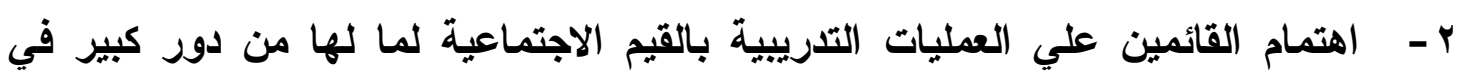

تطوير الجواتب الاجتماعية للاعبين.

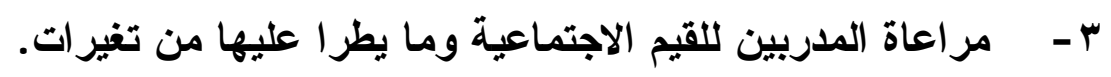

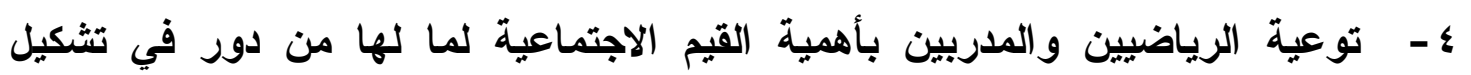

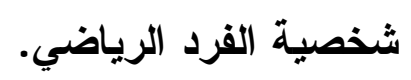




\section{المر اجع

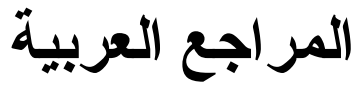

1- الحسني سعيد علي : دور القيم الاجتماعية في الوقاية من الجريمة، كلية الدر اسات العليا قسم العلوم الاجتماعية، جامعة نايف للعلوم النفسية و الاجتماعية

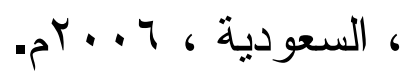

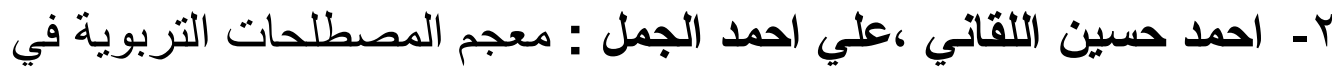

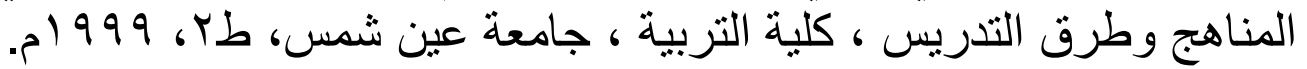

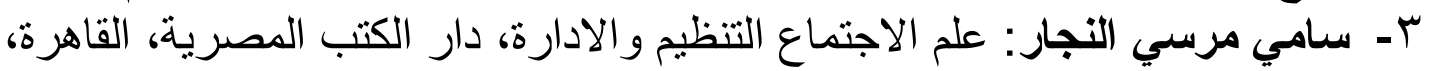

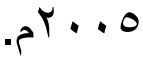

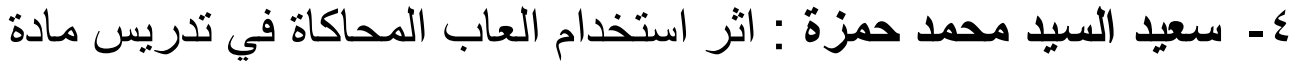

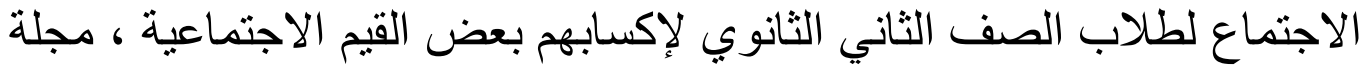

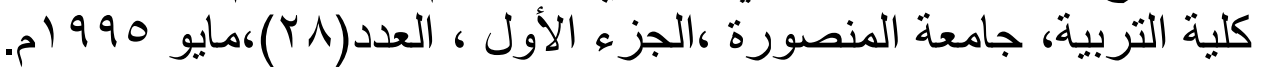

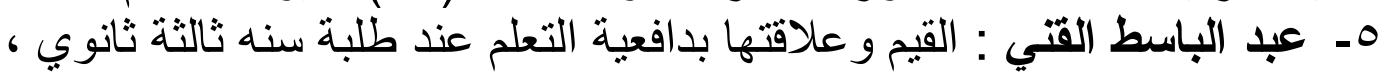

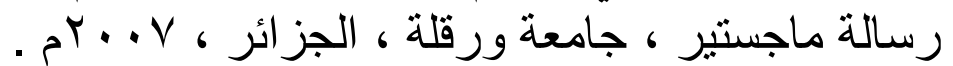

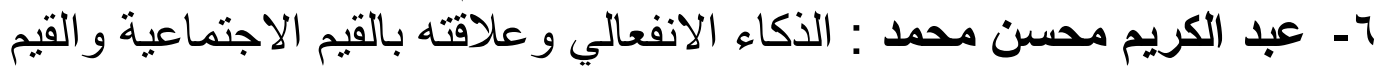

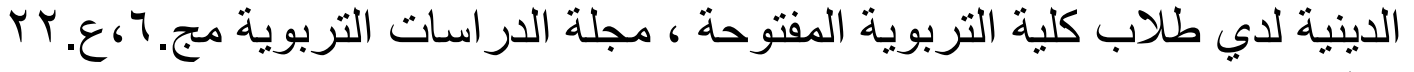

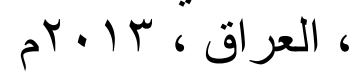

V - عبد اللطيف محمد خليفة : ارتقاء القيم ،در اسة نفسية، سلسلة عالم المعرفة

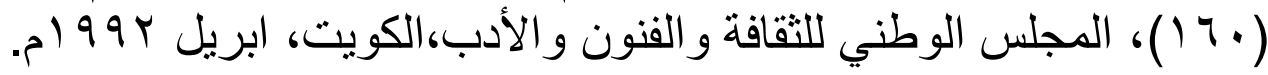

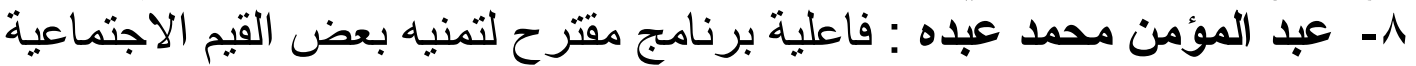

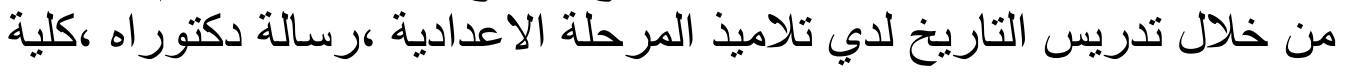

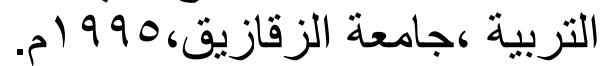

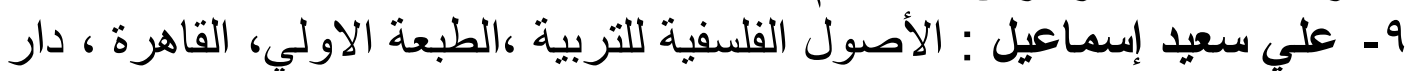

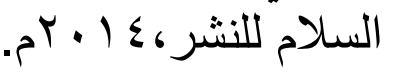
• 1 - تحي يوسف مبارك :بعض القيم الاجتماعية اللازمة لتلاميذ مرحلة التعليم

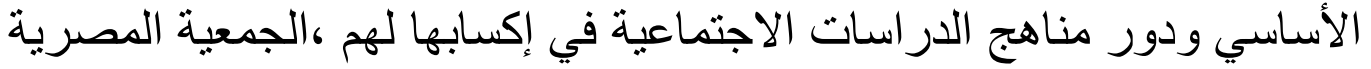

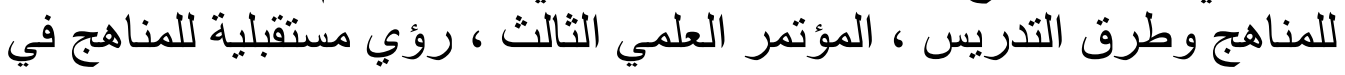

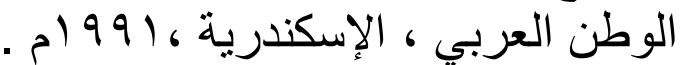

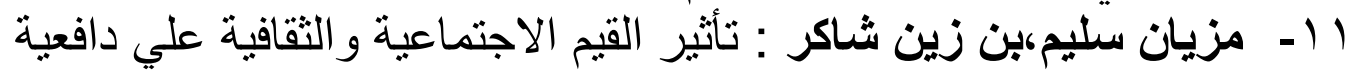

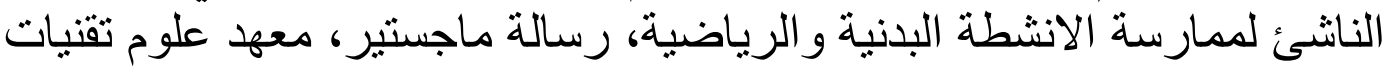

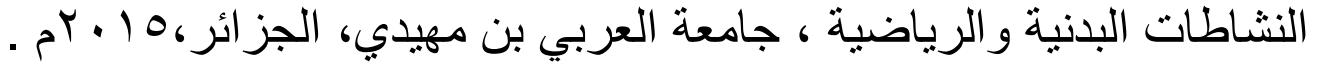

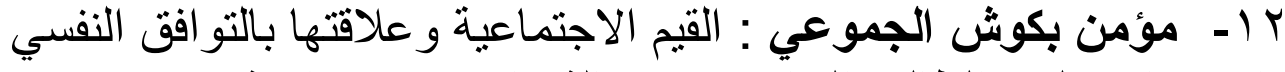

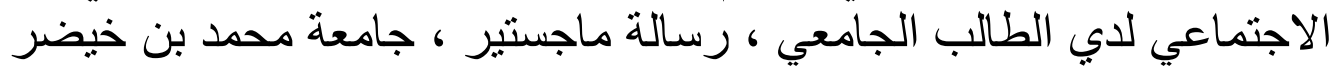

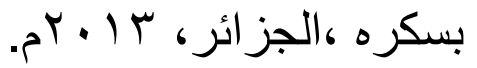




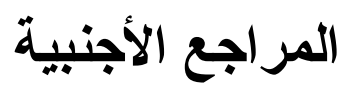

13-GrahmKOthers: the ethical behavior of teacher in an ir everchanging American social system K teacher education 1997:14 page.

14-Craig.p.EileenK(1989): The school as value perspective. London flamer press. 